Check for updates

Cite this: New J. Chem., 2020, 44, 3546

Received 21st December 2019, Accepted 31st January 2020

DOI: $10.1039 / c 9 n j 06330 \mathrm{~g}$

rsc.li/njc

\section{Recent advances in organic dyes and fluorophores comprising a 1,2,3-triazole moiety}

\author{
Damien Brunel (D) * and Frédéric Dumur (D) *
}

\begin{abstract}
Since the discovery of the copper catalyzed azide alkyne cycloaddition in the early 2000 s, tremendous efforts have been devoted to enlarging the scope of applications of this relatively simple to handle reaction. The chemistry of dyes has not been excluded from this enthusiasm so that a wide range of compounds have been synthesized over the years. Several key elements have sustained such research activity, such as the possibility to fine tune the photophysical properties, the easiness of structure screening in order to optimize the optical properties or the thermal stability of the triazole moiety. In this review, an overview of different dyes as well as their applications is reported.
\end{abstract}

\section{Introduction}

The independent discovery at the beginning of the 21st century of the copper-catalyzed version of the well-known azide-alkyne 1,3-dipolar cycloaddition by Medal and then Sharpless has enabled the introduction of the concept of click chemistry in modern chemistry. ${ }^{1,2}$ This cycloaddition reaction, also known as the Huisgen reaction and reported for the first time by Huisgen in the $60 \mathrm{~s},{ }^{3}$ has revolutionized the way to create molecules by its simplicity and its efficacy. Indeed, click chemistry consists in mimicking Nature, which fabricates natural substances by joining together elemental building blocks by means of a simple and easy reaction. More generally, click chemistry is based on reactions where two specific functional groups react together in soft conditions i.e. in non-dangerous solvents and at room temperature, without formation of by-products and in high yields. Moreover, the structures of the potential substrates being limitless, an infinite diversity of structures can be formed. Benefiting from this versatility, click chemistry was notably used to produce numerous molecules with applications ranging from pharmaceuticals ${ }^{4-6}$ to materials, ${ }^{7,8}$ modified alkaloids, ${ }^{9}$ carbohydrate chemistry, ${ }^{10}$ crop protection products (antifungal or pesticides), ${ }^{11,12}$ etc. ${ }^{13,14}$ The azide alkyne cycloaddition involves a reaction between an azide and an alkyne, producing a stable 1,2,3-triazole ring. The thermal cycloaddition of an azide and an alkyne furnishes most of the time a mixture of two regioisomers: the 1,4-disubstituted triazoles and the 1,5-disubstituted triazoles. Selectivity between the two regioisomers can however be obtained by a careful selection of the metal catalyst. Thus, CuAAC (copper catalyzed azide alkyne cycloaddition) is a convenient way to produce specifically the 1,4-triazole ring

Aix Marseille Univ, CNRS, ICR, UMR 7273, 13397 Marseille, France whereas ruthenium-catalyzed azide-alkyne cycloaddition (RuAAC) only provides the 1,5-regioisomers (see Scheme 1).

If click chemistry has been extensively studied for the design of molecules with biological applications, use of click chemistry for the design of chromophores and photoluminescent molecules is more scarce, even if the triazole ring can be advantageously used to connect under mild conditions an electron-donating group to an electron accepting group. ${ }^{15}$ Notably, the triazole ring offers a unique opportunity to give elaborate push-pull dyes which are now commonly used as photoinitiators of polymerization. ${ }^{16-23}$ Consequently, this heterocyclic five-membered ring is mainly used as a $\pi$-conjugated spacer ensuring electronic communication between the electron-donating and accepting moieties. In this review, an overview of the different chromophores and photoluminescent push-pull molecules prepared by click chemistry is presented. Beyond the synthesis of these compounds, the different applications in which these different structures have been used are also presented.

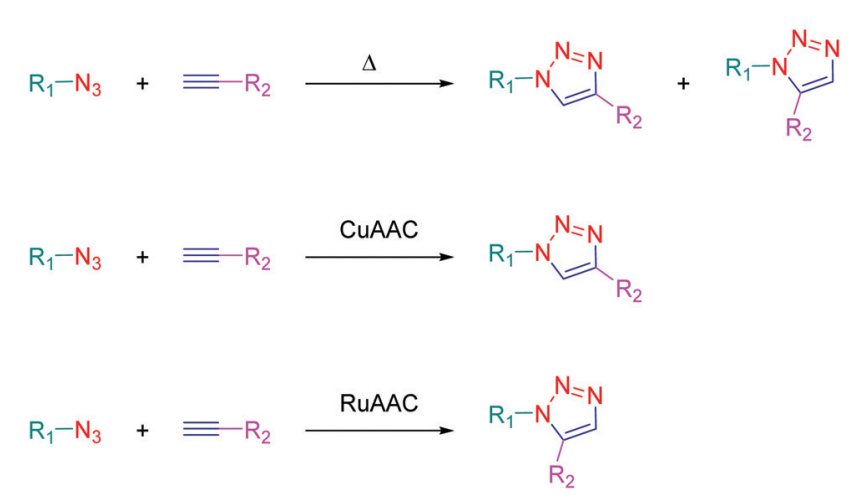

Scheme 1 The different types of cycloadditions based on the combination of an alkyne and an azide. 


\section{Push-pull molecules and light responsive organic molecules containing triazoles}

The association of an electron donor and an electron acceptor connected by means of a triazole ring was done for the first time in 2005 by Blanchard-Desce and coworkers. ${ }^{24,25}$ To examine the specificity introduced by the presence of the triazole ring in the push-pull dyes, a comparison was established between a series of dyes previously reported in the literature by the same authors and comprising alkene or alkyne spacers (i.e. compounds 1-3) and the newly developed triazole-based dyes 4 and 5 (see Fig. 1). ${ }^{26}$

Starting from the commercially available tris(4-ethynylphenyl)amine 6, 4,4'-diethynylbiphenyl 7 and $N$-(4-azidophenyl)- $N$ hexanoyl-hexanamide $\mathbf{8}$, the two products $\mathbf{4}$ and $\mathbf{5}$ could be formed in good yields, 68 and $86 \%$ respectively (see Scheme 2). The optical properties of the two dyes 4 and 5 were compared with those of their analogues 1-3 comprising $\pi$-conjugated spacers classically used for the design of push-pull dyes (see Table 1). ${ }^{27}$ While comparing the absorption properties of the star-shaped dyes 1 and 4, a hypsochromic shift of $c a .40 \mathrm{~nm}$ of the position of the intramolecular charge transfer (ICT) band could be observed for 4 compared to that of 1. Similarly, a twofold reduction of the photoluminescence quantum yield (PLQY) for $\mathbf{4}$ compared to that of $\mathbf{1}$ was also detected. A more severe reduction of the PLQY was demonstrated for $\mathbf{5}$, the latter being divided by a factor 3.9 compared to that of its analogue 2 . While examining the order of the ICT bands, the most blue-shifted ICT band was found for 5 bearing the triazole ring, followed by

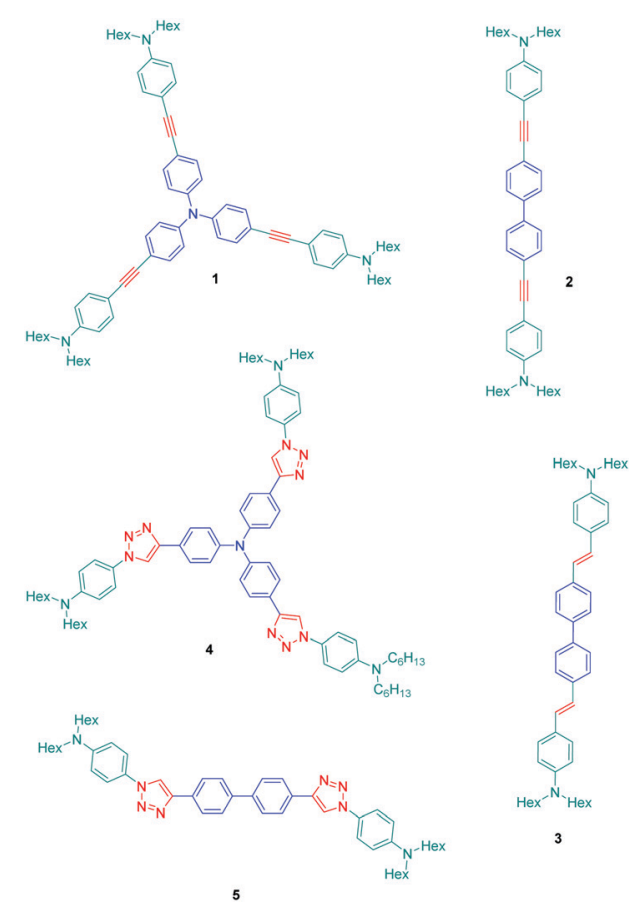

Fig. 1 Structures of triazole-based dyes $\mathbf{4}$ and $\mathbf{5}$ and their alkyne/alkene bridged analogues 1-3.
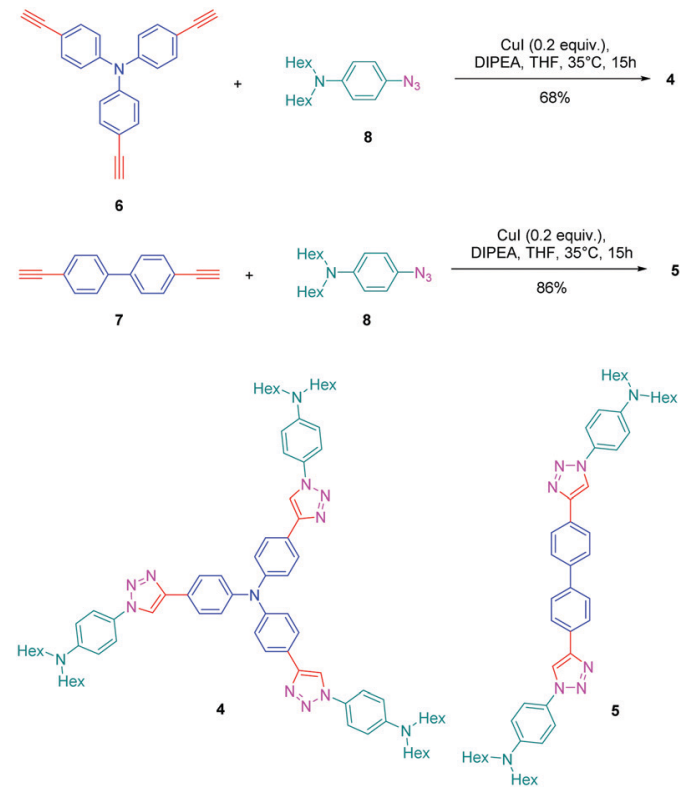

Scheme 2 Synthetic pathways to 4 and $\mathbf{5}$.

Table 1 Photophysical characteristics of triazole-based dyes 1-5 in toluene

\begin{tabular}{llllll}
\hline Molecules & $\lambda_{\mathrm{abs}}{ }^{a}(\mathrm{~nm})$ & $\lambda_{\mathrm{em}}{ }^{a}(\mathrm{~nm})$ & $\Phi_{\mathrm{F}}{ }^{b}$ & Stokes shift $\left(\mathrm{cm}^{-1}\right)$ & Ref. \\
\hline $\mathbf{1}$ & 385 & 411 & 0.77 & 1634 & 6 \\
$\mathbf{4}$ & 347 & 387 & 0.49 & 3000 & 9 \\
$\mathbf{2}$ & 374 & 424 & 0.90 & 3200 & 9 \\
$\mathbf{3}$ & 401 & 456 & 0.84 & 3000 & 9 \\
$\mathbf{5}$ & 325 & 391 & 0.23 & 5100 & 6
\end{tabular}

${ }^{a}$ Recorded in toluene. ${ }^{b}$ Photoluminescence quantum yield.

2 and 3 bearing an alkene and an alkyne spacer respectively. Therefore, it can be concluded that the 1,2,3-triazole ring is the worse candidate to connect the electron donor to the electron acceptor, the blue-shift of the ICT band being indicative of a lack of electronic communication between the two partners.

If the detrimental effect of the 1,2,3-triazole ring on the electronic delocalization of $\mathbf{4}$ and $\mathbf{5}$ could be easily evidenced with a significant reduction of the PLQYs and a blue-shift of the ICT bands compared to those of 1-3, conversely, the greatest Stokes shifts were determined for these dyes. Indeed, if Stokes shifts of 3200 and $3000 \mathrm{~cm}^{-1}$ were found for 2 and 3 respectively, this value increased up to $5100 \mathrm{~cm}^{-1}$ for the triazole-based dye 5 . Therefore, based on the large Stokes shifts, it can be concluded that a major electronic redistribution occurs prior to emission. Following this pioneering work, several derivatives still based on the triphenylamine electron donor were prepared and examined for their photophysical properties. In fact, triphenylamine is at the basis of numerous compounds developed for photovoltaic applications due to its remarkable charge transport ability and its low oxidation potential. ${ }^{28-36}$ The chemical structures of the different triphenylamine-based dyes $\mathbf{9 - 1 1}$ synthesized by click chemistry are presented in Fig. 2. ${ }^{37}$ To prepare 9-11, mono, bis and tris-ethynylsubstituted triphenylamines 12-14 were engaged in reactions with 3-(4-azido-2,5-bis(hexyloxy)phenyl)-2-cyano-acrylic acid 15 

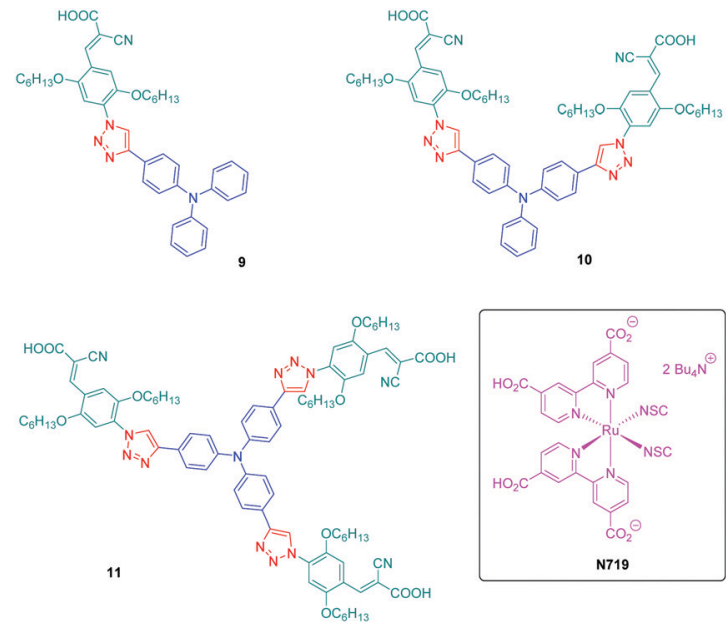

Fig. 2 The three triphenylamine-based dyes 9-11 and the reference dye N719.

in a $\mathrm{THF}-\mathrm{H}_{2} \mathrm{O}$ mixture using sodium ascorbate and copper sulfate as the catalysts. 9-11 could be prepared with reaction yields ranging from 77 to $87 \%$. 3-(4-Azido-2,5-bis(hexyloxy)phenyl)-2cyanoacrylic acid 15, which constitutes the precursor of the electron accepting part of the push-pull dyes 9-11, is substituted with a cyanoacetic acid moiety favourable for the adsorption of the dye onto the $\mathrm{TiO}_{2}$ electrode. This intermediate could be prepared in a 4 -step procedure depicted in Scheme $3 .^{33,38}$

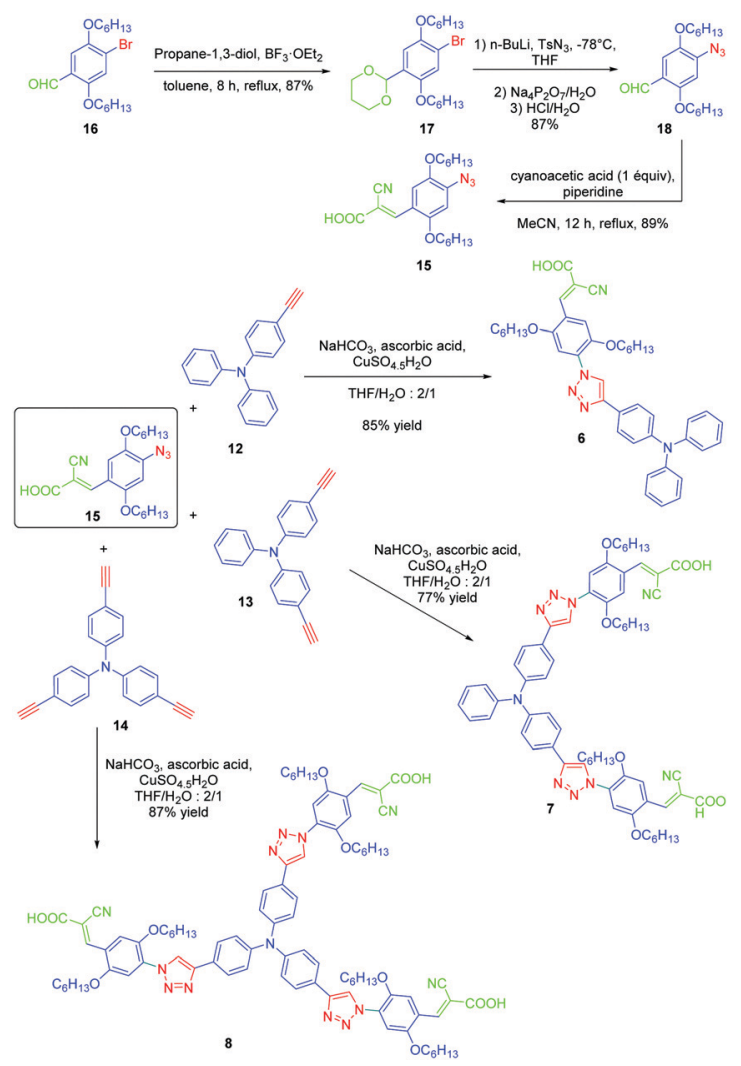

Scheme 3 Synthetic routes to 3-(4-azido-2,5-bis(hexyloxy)phenyl)-2cyanoacrylic acid $\mathbf{1 5}$ later used for the synthesis of 9-11.
Notably, after protection of the aldehyde group of $\mathbf{1 6}$ with propane-1,3-diol, acetal 17 could be formed in 87\% yield. Finally, the azido group could be introduced in $87 \%$ yield using $n$-butyl lithium as the base. After deprotection of the aldehyde, a Knoevenagel reaction carried out on 18 with cyanoacetic acid provided the targeted intermediate 15 in $89 \%$ yield.

9-11 were analysed by UV-visible absorption spectroscopy and cyclic voltammetry, and finally characterized as potential candidates for dye sensitized solar cells (DSSCs). The efficiencies of the corresponding solar cells remained moderate, the photon-to-electron conversion efficiency peaking at 3.00\% for 9 (see Table 2). Interestingly, a reduction of the energy conversion efficiency was found while increasing the number of branches on the triphenylamine moiety, which was attributed to a reduced density of molecules on the $\mathrm{TiO}_{2}$ anode. Indeed, by increasing the number of branches, a dramatic increase of the molecule size occurs requiring more space to be attached on the electrode, thus lowering the photon-to-electron conversion. All dyes showed a broad absorption band in the solid state ranging between $300 \mathrm{~nm}$ and $500 \mathrm{~nm}$ with a long tail extending until $700 \mathrm{~nm}$. More precisely, for 9 and 10, the absorption spectra showed two peaks, one around $310 \mathrm{~nm}$ attributable to $\pi-\pi^{*}$ transitions and a second one at $400 \mathrm{~nm}$ corresponding to the ICT band. Conversely, for 11, a strong overlap of the $\pi-\pi^{*}$ transitions and the ICT band was found so that the absorption band at high energy was detected as a simple shoulder of the ICT band. The bathochromic shift of the ICT bands from 11 to $\mathbf{9}$ can be explained by a higher polarity of the molecule upon reduction of the branch number, facilitating the delocalization of electrons upon photoexcitation.

Theoretical calculations revealed the HOMO and LUMO energy levels of 9-11 to be spatially well-separated thanks to the presence of the triazole group. Indeed, the HOMO level was determined as being centered on the triphenylamine moiety whereas the LUMO level was localized on the anchoring group (i.e. the cyanoacetic acid group). Due to this well-defined separation between the HOMO and LUMO energy levels, efficient injection of the electrons into the conduction band of $\mathrm{TiO}_{2}$ is expected upon photoexcitation. Cyclic voltammetry showed the dyes to be good candidates for photovoltaic applications due to their energy levels perfectly fitting with those of the adjacent layers. Notably, the position of the LUMO level at $-3.50 \mathrm{eV}$ is favourable for electron injection into the conduction band of $\mathrm{TiO}_{2}$.

Table 2 Properties of the triphenylamine-based dyes 9-11

\begin{tabular}{llllll}
\hline & $\begin{array}{l}\lambda_{\max }{ }^{a} \\
\text { Dye }\end{array}$ & $\begin{array}{l}\varepsilon^{b} \\
\left(10^{4} \mathrm{M}^{-1} \mathrm{~cm}^{-1}\right)\end{array}$ & $\begin{array}{l}E_{\text {red }}(\mathrm{V}) / \\
\mathrm{LUMO}^{c}(\mathrm{eV})\end{array}$ & $\begin{array}{l}E_{\text {ox }}(\mathrm{V}) / \\
\mathrm{HOMO}^{d}(\mathrm{eV})\end{array}$ & $\eta(\%)$ \\
\hline $\mathbf{9}$ & 312,388 & $3.28,1.51$ & $-0.86 /-3.50$ & $0.96 /-5.32$ & 3.00 \\
$\mathbf{1 0}$ & 320,405 & $6.00,3.73$ & $-0.83 /-3.54$ & $0.91 /-5.28$ & 2.13 \\
$\mathbf{1 1}$ & 348 & 6.08 & $-0.81 /-3.51$ & $0.98 /-5.3$ & 1.58 \\
N719 & - & - & - & - & 4.86
\end{tabular}

${ }^{a}$ In dioxane with $C=1 \times 10^{-5}$ M. ${ }^{b}$ Molar extinction coefficient at $\lambda_{\max }$ in solution. ${ }^{c}$ Estimated from the onset reduction potential/calculated with the formula $E_{\mathrm{LUMO}}(\mathrm{eV})=-\left(E_{\mathrm{red}}+\left[4.8-E_{\left(\mathrm{Fc}_{\mathrm{Fc}}\right)}\right]\right) \mathrm{eV}$. ${ }^{d}$ Estimated from the onset oxidation potential/calculated with the formula $E_{\text {Hомо }}(\mathrm{eV})=$ $-\left(E_{\mathrm{Ox}}+\left[4.8-E_{\left(\mathrm{Fc}^{\mathrm{Fc}} \mathrm{j}\right)}\right]\right)$. 
Similarly, the position of the HOMO level at $-5.30 \mathrm{eV}$ is lower than that of the $\mathrm{I}^{-} / \mathrm{I}_{3}{ }^{-}$redox potential so that the different dyes can be efficiently regenerated during device operation. ${ }^{39,40}$ Parallel to the molecular size, which increases with the number of branches on the triphenylamine core, the low energy conversion efficiency could also be assigned to the limited absorption ability of triazole-linked push-pull dyes 9-11, only partially covering the solar spectrum. On the contrary, the reference device fabricated with $\mathbf{N 7 1 9}$ could provide a higher conversion efficiency by overcoming this drawback (see Table 2). Notably, N719 exhibits two main absorption bands at 380 and $550 \mathrm{~nm}$ so that its absorption spectrum almost extends from 350 until $800 \mathrm{~nm}$.

To establish a clear structure-performance relationship, the synthesis of numerous derivatives is a prerequisite. This hard work was notably done with a series of twelve dyes (19-30) prepared by click chemistry and comprising a 1,2,3-triazole ring. In this context, guidelines concerning the introduction of 1,2,3-triazole rings in push-pull dyes could be established. The photophysical properties of these dyes were compared to an analogue series (31-33) composed of 3 dyes bearing a phenyl spacer instead of the triazole ring. ${ }^{41}$ In fact, to clearly evidence the real impact of the triazole ring on the photophysical properties, two series of triazole-based dyes were prepared, the first one (19-27) bearing the five-membered ring in an inverted position compared to the second one (28-30), generating two groups of regioisomers (see Scheme 4 and Fig. 3).

From a synthetic point of view, the first series (19-27) was prepared while using the azide group attached to the electrondonating moiety (34-36). The click reaction carried out under microwave irradiation could provide the different dyes with reaction yields ranging from 54 to $91 \%$ upon irradiating the solutions for 30-60 minutes. On the contrary, for the inverted series, the synthetic procedure should be modified for the preparation of $\mathbf{2 9}$ and 30, 2-azidopyridine and 2-azidopyrimidine being less reactive than azidobenzene due to the formation of the tetrazole ring by tautomeric equilibrium. In this context,
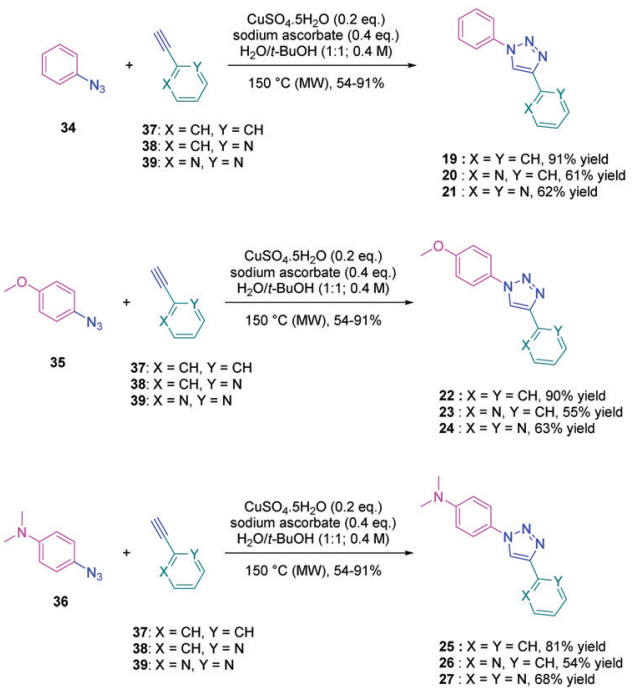

$21: X=N=N, 62 \%$ yield
21:

Scheme 4 Chemical structures and synthetic routes to 19-27.

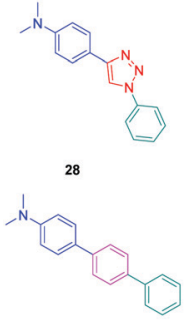

31

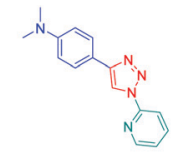

29

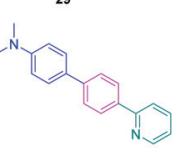

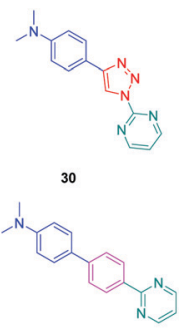

33
Fig. 3 Second series of push-pull molecules $28-33$.

classical thermal conditions were used. By refluxing in toluene with traces of benzene and while using copper triflate as the catalyst, 29 and 30 could be prepared in $68 \%$ and $12 \%$ yield respectively (see Scheme 5). Noticeably, if traces of benzene in toluene seem to be required for the reaction to proceed, no justification for its presence was mentioned by the authors. Finally, the three reference compounds 31-33 were obtained by a Suzuki cross-coupling reaction of bromobenzene, bromopyridine, or bromopyrimidine with the corresponding boronic ester (see Scheme 5). 31, 32 and 33 could be obtained with reaction yields ranging from 49 to $86 \%$.

The photophysical properties of the three series (19-27, 28-30, and 31-33) were examined to explore the exact role of the triazole spacer in the intramolecular charge transfer process. It has to be noticed that prior to this work, a similar comparison was made from a theoretical point of view by Catan and coworkers of 25 and 28 and the conclusions are consistent with those found in this work. ${ }^{42,43}$ A summary of the absorption properties is provided in Table 3. As first findings, the different dyes 19-27 showed no or only weak emission in dichloromethane. Precisely, no emission could be detected for all dyes comprising a benzene ring as the electron donor. While comparing the variation of the absorption maximum for the same electron acceptor, a red-shift of the absorption maximum with the electron-releasing ability of the 
Table 3 UV-visible characteristics of push-pull molecules reported in ref. 27

\begin{tabular}{|c|c|c|c|c|}
\hline Dyes & $\lambda_{\mathrm{abs}}{ }^{a}(\mathrm{~nm})$ & $\begin{array}{l}\varepsilon^{a} \\
\left(\mathrm{M}^{-1} \mathrm{~cm}^{-1}\right)\end{array}$ & $\begin{array}{l}\lambda_{\mathrm{em}}{ }^{a} \\
(\mathrm{~nm})\end{array}$ & $\begin{array}{l}k^{b} \\
\left(\mathrm{~cm}^{-1}\right)\end{array}$ \\
\hline 19 & 250, 266 (sh), 272 (sh), 282 (sh), 289 (sh) & 23140 & n.o. ${ }^{c}$ & - \\
\hline 20 & 286 & 23140 & n.o. ${ }^{c}$ & - \\
\hline 21 & 255 & 4020 & n.o. ${ }^{c}$ & - \\
\hline 22 & $256,267(\mathrm{sh}), 273(\mathrm{sh})$ & 25120 & n.o. ${ }^{c}$ & - \\
\hline 23 & $282(\mathrm{sh}), 289$ (sh) & 25600 & n.o. ${ }^{c}$ & - \\
\hline 24 & 287 & 27180 & 392 & 6087 \\
\hline 25 & 263 & 24380 & n.o. ${ }^{c}$ & - \\
\hline 26 & 286 (sh), 302 & 20940 & 396 & 12729 \\
\hline 27 & 306 & 23920 & 413 & 22048 \\
\hline 28 & 309 & 20020 & 454 & 27609 \\
\hline 29 & 270 (sh), 302 & 28480 & 438 & 23228 \\
\hline 30 & 271 (sh), 296, 305 (sh), 345 (sh) & 27660 & 470 & 26593 \\
\hline 31 & 268 (sh), 287, 310 (sh), 345 (sh) & 16760 & n.o. ${ }^{c}$ & - \\
\hline 32 & 325 & 34320 & 419 & 13028 \\
\hline 33 & 337 & 27640 & 449 & 18636 \\
\hline
\end{tabular}

${ }^{a}$ Determined in dichloromethane with $C=5 \mu \mathrm{M} .{ }^{b}$ Slope of the linear correlation of the Stokes shift with the solvent orientation polarizability determined from the Lippert-Mataga plots. ${ }^{c}$ Not observed.

donor was observed. Parallel to this, by improving the electronwithdrawing ability of the acceptor, a red-shift of the absorption maximum was similarly observed. While comparing with the reference series 31-33 comprising a benzene ring as the spacer, a larger red-shift of the absorption maximum with the donor strength was found $\left(\Delta \lambda_{\max }=26 \mathrm{~nm}\right)$ for this series (31-33) compared to the series (19-27) comprising the triazole group $\left(\Delta \lambda_{\max }=7 \mathrm{~nm}\right)$. This higher shift of the absorption maximum was assigned to a higher charge redistribution upon photoexcitation, evidencing better conjugation between the donor and the acceptor when a benzene ring is used as a spacer. The higher conjugation degree for the benzene-based series was also demonstrated while comparing the absorption maxima for $\mathbf{2 8}$ and 31, respectively detected at 302 and $323 \mathrm{~nm}$. Finally, the solvatochromism of the different dyes was rationalized using the LippertMataga equation. ${ }^{43}$ In all cases, a linear correlation was found, demonstrating the validity of the model. In this equation, the variation of the Stokes shift with the solvent polarity is examined, and the slope of the plots is directly related to the difference existing between the dipole moments in the ground and the excited state. Logically, for identical electron donors, a steeper slope was found while increasing the electron-accepting ability. But a deeper insight into the linear correlations unveiled more complex processes. Notably, comparison of the slopes for 28 and 31 revealed similar values, demonstrating that a similar charge redistribution occurs upon excitation. However, examination of the absorption and emission maxima of $\mathbf{2 8}$ and $\mathbf{3 1}$ also evidences the two maxima to be red-shifted for $\mathbf{3 1}$ compared to $\mathbf{2 8}$, consistent with a higher conjugation degree for the dyes comprising a benzene spacer. Therefore, it was concluded from these different results that if better electronic conjugation exists in the ground state for the dyes (31-33) comprising a benzene spacer, higher charge transfer occurs for the triazole-based dyes (19-27) comprising a strong electron acceptor such as a pyridine or a pyrimidine moiety. Conversely, similar charge transfer is observed for the dyes comprising a weak electron acceptor such as benzene.
Comparison of the regular series $(25,26$ and 27) with the inverted series (i.e. 28, 29, and 30) revealed redshifted absorption for the inverted series. Comparison of the slopes of the LippertMataga correlation of the regular and inverted series for dyes (25-27 vs. 28-30) comprising a strong electron acceptor also revealed the slopes for the inverted series (28-30) to be more pronounced than those of the regular series (25-27).

From these observations, it was concluded that for the inverted series, the triazole ring was acting as an electron acceptor. Overall, the orientation of the triazole ring in the regioisomers can efficiently influence the photophysical properties of the push-pull dyes. For most of the abovementioned dyes, crystals could be grown so that their Non-Linear Optical (NLO) response could be examined. However, as a prerequisite, only structures crystallizing in a non-centrosymmetric arrangement could be considered for their capabilities to produce a non-linear response. Among all dyes, only 22, 23 and $\mathbf{2 4}$ were analyzed for their Second Harmonic Generation (SHG) efficiencies while using potassium dihydrogen phosphate (KDP) as a reference.

As predicted by the two-state model, ${ }^{44}$ the best non-linear response was obtained for the dye exhibiting the strongest charge redistribution upon excitation and the non-linear response of $\mathbf{2 4}$ was 80 times higher than that of KDP. Conversely, the SHG efficiencies of 22 and 23 were 3.4 and 6 times higher than that of KDP. Prior to this work, numerous studies were carried out by the group of Fröhlich et al. on push-pull dyes comprising the 1,2,3-triazole ring as an electron-acceptor. In this field, the first report was published in 2011 with 47 crystallizing in the space group $P 2{ }_{1} 2_{1} 2_{1}$. This compound could be prepared in two steps, by thiophene-ring fragmentation (TRF) of (3-bromo-5-methylthiophen-2-yl)trimethylsilane. ${ }^{45-47}$ Following the formation of the intermediate enyne, the click reaction of azidobenzene with the enyne derivative could provide the expected dye as the unique 1,4-regioisomer in $75 \%$ yield by using microwave irradiation (see Scheme 6).

Conversely, all attempts of synthesis using thermal conditions could only furnish 47 in 58\% yield after 18 hours of heating at $50{ }^{\circ} \mathrm{C}$. Importantly, the $Z$-geometry of $\mathbf{4 7}$ was of crucial importance to produce none-centrosymmetric crystals. Examination of the SHG response while exciting at $1064 \mathrm{~nm}$ revealed the NLO response to be two times higher than that of KDP.

Considering that the 1,2,3-triazole group acts as an electron acceptor in these structures, $\mathbf{4 7}$ was revisited in a more extended study (47 and 51-59) in which ten different groups were attached onto the five-membered ring (see Fig. 4$).{ }^{48}$

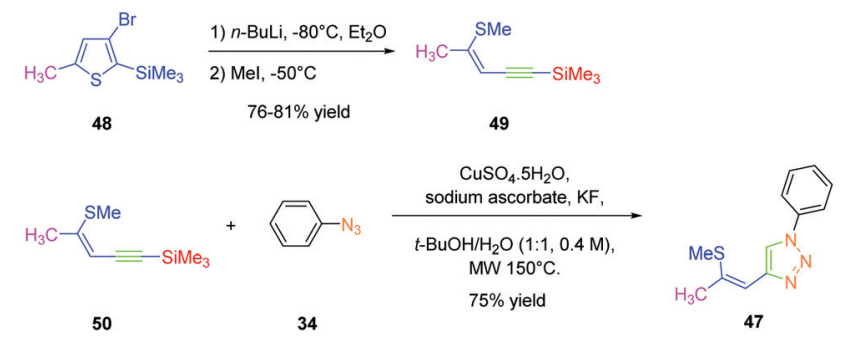

Scheme 6 Synthetic route to the push-pull dye 47. 


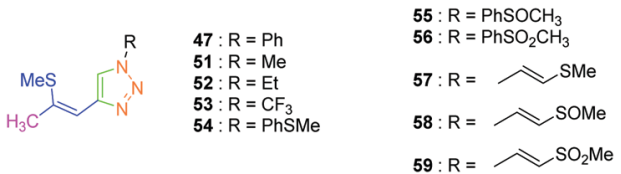

Fig. 4 Chemical structures of 47 and 51-59.

While examining the substituent effects, substitution of the 1,2,3-triazole ring with aromatic rings (54-56) was determined as being preferable over vinylic (57-59) or aliphatic groups (51-53). Finally, for aromatic rings, the methylsulfone group (55) proved to be the best substituent for maximizing the hyperpolarizability tensors. Compared to $\mathbf{4 7}$ comprising an unsubstituted aromatic ring, an enhancement of the NLO response by a factor 3.5 was obtained for $\mathbf{5 6}$ substituted with a sulfone moiety (see Table 4).

Click chemistry being a versatile technique enabling one to perfectly control the regioselectivity, a comparison between 1,2 and 1,4-regioisomers was established. ${ }^{49}$ Different groups were introduced onto the electron-donating thiol moiety, namely, methyl, ethyl, propyl and butyl groups. The different alkynes $\mathbf{5 0}$ and 60-64 were obtained by ring-opening of the thiophene derivatives 48,65 , and 66 . By applying a copper-catalysed click reaction to 50 and 60-64, six different dyes 47 and 67-71 could be prepared with reaction yields ranging from 61 to $75 \%$. Reflux in the presence of a catalytic amount of acid $(\mathrm{HCl})$ could partially isomerize the $Z$-isomers $\mathbf{4 7}, \mathbf{6 8}, \mathbf{7 0}$ and $\mathbf{7 1}$ into the $E$-isomers 72, 73, 74 and 75 respectively in moderate yields (see Scheme 7). Indeed, for all dyes $\mathbf{4 7}$ and $\mathbf{6 7 - 7 5}$, preparative thin layer chromatography (TLC) was required to separate the two isomers, providing in turn the $E$-isomers only in low yields. On the contrary, the ruthenium-catalyzed click reaction selectively furnished the 1,2-regioisomer. In this last case, only one derivative was prepared, namely 77 in 39\% yield, starting from $\mathbf{7 6}$ formed by deprotection of the silyl group of 50. Examination of the crystal structures of the different dyes revealed 70, 71, 72 and 77 to be unsuitable for NLO measurements due to centrosymmetric crystallization. Finally, the SHG signal detected for the 4-series was relatively low for two dyes i.e. $\mathbf{4 7}$ and $\mathbf{6 8}$ and no signals were detected for the others.

Isomerization of the double bond only provided the 72-74-series crystallizing in a centrosymmetric arrangement. Modification of the substitution on the 1,2,3-triazole ring did not significantly modify the NLO response of 77, approaching that of its 1,4-regioisomer 47. Upon oxidation of the sulphur atom (78 and 79), the opposite situation to that found for the previous series could be created. Oxidation of sulphur to sulfone converted the electron-donating

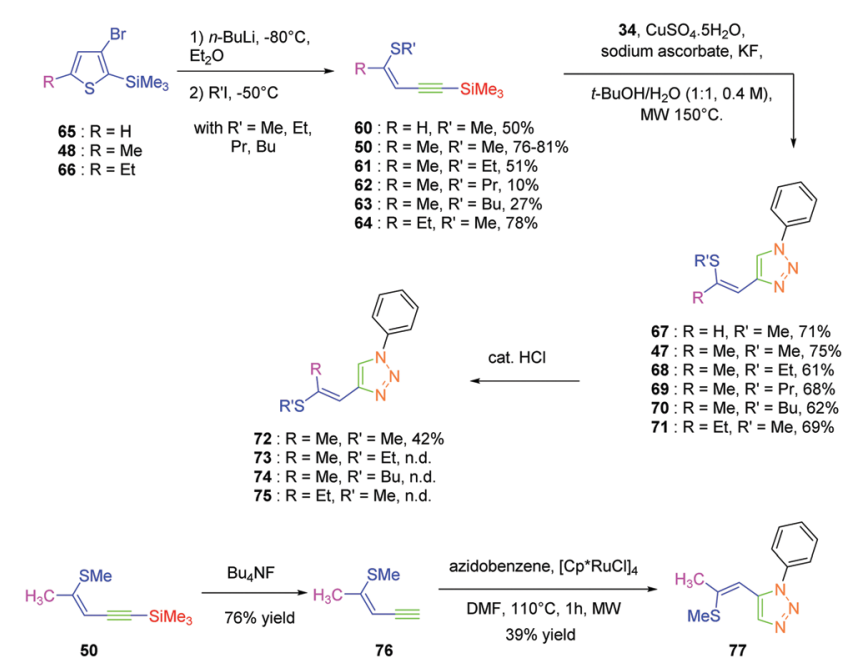

Scheme 7 Synthetic route to $47,67-71$ and 77
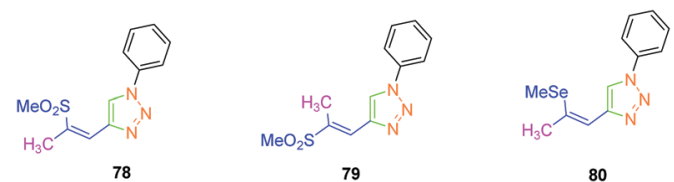

Fig. 5 Chemical structures of $\mathbf{7 8 - 8 0}$

group (sulphur) to the electron-accepting group (sulfone), inverting the push-pull effect. Two stereoisomers were prepared, namely $\mathbf{7 8}$ and 79 differing in the configuration of the double bond. While comparing $\mathbf{7 4}$ with its parent $\mathbf{4 7}$, an enhancement of the NLO response by about $45 \%$ was found. Finally, the best results were obtained with the selenium-based analogue of 47 i.e. 80 (see Fig. 5). In this last case, the NLO response was enhanced by a factor of 20 , resulting from the increased electron density in the $\pi$-conjugated system.

In 2017, the highest SHG efficiency ever reported for this family of dyes was reported by the same authors. ${ }^{50}$ Interestingly, a great deal of effort was devoted to improving the synthetic route to these dyes with regards to the safety, the selectivity and the quantity of materials available at each step. By substituting 81, 54 and 82 with methoxy, thiomethoxy and dimethylamino groups, D-A-D triads could be obtained (see Fig. 6). If $\mathbf{5 4}$ and 82 were determined as crystallizing in centrosymmetric arrangements, 81 crystallized in the $P 2_{1 / C}$ space group and showed an SHG response 80 times higher than the reference KDP.

In the previous studies of Fröhlich, substituents positioned on the 1,2,3-triazole ring were demonstrated to have no influence on

Table 4 Hyperpolarisability tensors in atomic units (a.u.) for the dyes 47 and 51-59

\begin{tabular}{lllllllll}
\hline Dyes & $\mathbf{4 7}$ & $\mathbf{5 1}$ & $\mathbf{5 2}$ & $\mathbf{5 3}$ & $\mathbf{5 4}$ & $\mathbf{5 5}$ & $\mathbf{5 6}$ & $\mathbf{5 7}$ \\
\hline$\beta_{\text {tot }}$ & 0.37 & 0.41 & 0.51 & 1.72 & 2.39 & 2.69 & 4.44 & \\
\hline Dyes & & & $\mathbf{5 8}$ & & & \\
\hline$\beta_{\text {tot }}$ & & & 2.52 & &
\end{tabular}



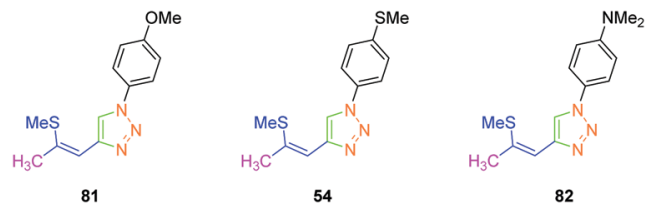

Fig. 6 Chemical structures of 54, 81 and 82

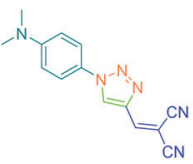

83

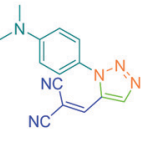

84

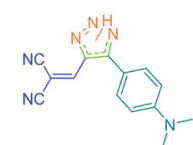

85

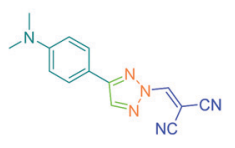

86
Fig. 7 The four positional isomers of dicyanovinyl-triazole-dimethylaminobenzene compounds 83-86.

the SHG response, as quite similar responses were obtained with 1,2- and 1,4-regioisomers. This parameter was earlier studied by Diederich et al. and opposite conclusions were then established with 83-86 (see Fig. 7). ${ }^{51}$ For this study, if potentially seven constitutional isomers could be prepared differing in the position of the electron-donating and electron-accepting groups around the triazole group, only four of them 83-86 were obtained.

From a synthetic point of view, the design of these four dyes proved to be a challenge. As shown in Scheme 8, 83 could only be obtained using a two-step procedure, by first performing the click reaction with propynal 87 and 4 -azido- $N, N$-dimethylaniline 36 and by subsequently realizing the Knoevenagel reaction of 88. Conversely, attempts of the click reaction with 4-azido- $N, N$ dimethylaniline 36 and 2-(3-(trimethylsilyl)prop-2-yn-1-ylidene)malononitrile 89 only furnished 83 in low reaction yields ( $>5 \%)$. The reaction of 2-(3-(trimethylsilyl)prop-2-yn-1-ylidene) malononitrile 89 and 4 -azido- $N, N$-dimethylaniline 36 was more efficient to prepare the 1,2-regioisomer 90. In this last case, click chemistry was not the reaction used to prepare 90 but a thermal 1,3-dipolar cycloaddition. After 5 days of reflux, the intermediate silylated derivatives could be obtained in $18 \%$ yield and desilylation of 91 with methanol furnished 90 in $78 \%$ yield (see Scheme 9). If the reaction was low-yielding, the formation of $\mathbf{9 0}$ was highly selective, resulting from the bulkiness of the trimethylsilyl group.

Concerning 85 and $\mathbf{8 6}$, the two molecules were synthesized by alternative synthetic routes to click chemistry or the thermal

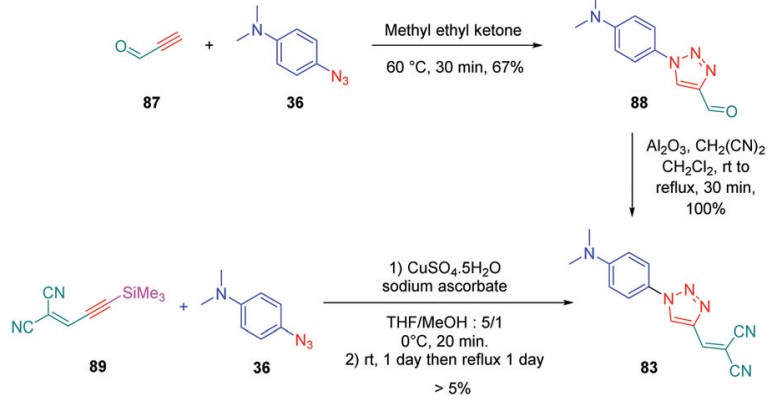

Scheme 8 Synthetic pathway of $\mathbf{8 3}$.

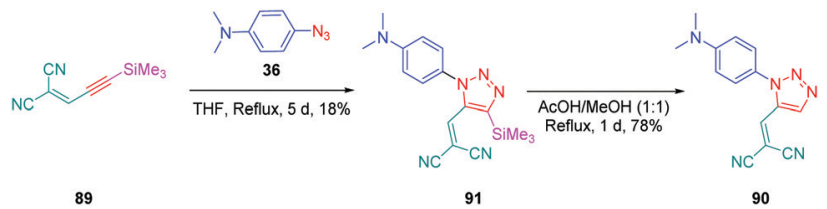

Scheme 9 The two-step synthetic route to 90 .

Huisgen reaction, these two procedures being unable to provide the two expected products. Thus, to prepare 85, a simple cycloaddition reaction of 2-(3-(4-(dimethylamino)phenyl)prop-2-yn-1-ylidene)malononitrile 92 with sodium azide upon heating at $100{ }^{\circ} \mathrm{C}$ formed 85 in $61 \%$ yield.

Conversely, 86 was obtained in more steps, the first one consisting of the click reaction between azidomethyl pivalate $\mathbf{9 3}$ and 4-ethynyl- $N, N$-dimethylaniline 94, furnishing after basic treatment 73 in 51\% yield. By an addition/elimination reaction of $\mathrm{N}, \mathrm{N}$-dimethyl-4-(2H-1,2,3-triazol-4-yl)aniline 95 with (chloromethylidene) propanedinitrile 96 carried out at room temperature, 86 could be obtained in 63\% yield (see Scheme 10).

To examine the effect of the 1,2,3-triazole ring on the electronic delocalization between the electron-donating dimethylaminophenyl group and the electron accepting dicyanomethylidene group, a comparison of the photophysical properties of 83-86 was established with those of $\mathbf{9 7 ^ { 5 2 }}$ and $\mathbf{9 8}^{53}$ previously reported in the literature. Precisely, the nature of the spacer and the number of carbon atoms between the donor and the acceptor were determined in previous work of the same group as being determinants of the photophysical properties of the dyes. In this context, 97 and 98 were selected for the comparison due to the similarity in the length of their $\pi$-conjugated spacers (see Fig. 8 and Table 5). ${ }^{54}$
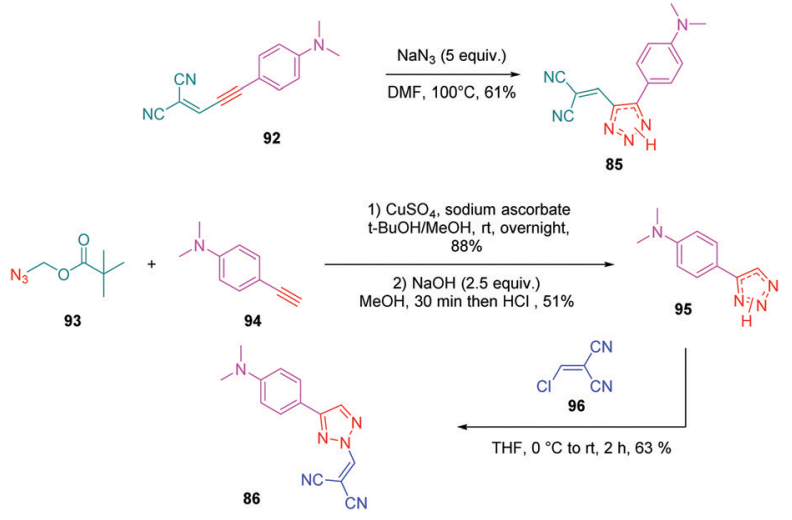

Scheme 10 Synthetic routes to $\mathbf{8 5}$ and $\mathbf{8 6}$

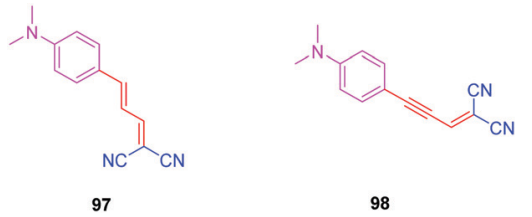

Fig. 8 Chemical structures of $\mathbf{9 7}$ and $\mathbf{9 8}$ 
Table 5 Optical properties of $\mathbf{8 3 - 8 6 , 9 7}$ and $\mathbf{9 8}$

\begin{tabular}{llcl}
\hline Dyes & $\lambda_{\text {abs }}(\mathrm{nm})$ & $\varepsilon\left(\mathrm{M}^{-1} \mathrm{~cm}^{-1}\right)$ & Ref. \\
\hline $\mathbf{8 3}$ & 400 & 8100 & 40 \\
$\mathbf{8 4}$ & 433 & 2500 & 40 \\
$\mathbf{8 5}$ & 423 & 11300 & 40 \\
$\mathbf{8 6}$ & 453 & 7300 & 40 \\
$\mathbf{9 7}$ & 477 & 44100 & 40 \\
$\mathbf{9 8}$ & 488 & 47000 & 42
\end{tabular}

All spectra were recorded in $\mathrm{CH}_{2} \mathrm{Cl}_{2}$ at $298 \mathrm{~K}$.

As the first finding, a clear reduction of the conjugation upon incorporation of the 1,2,3-triazole ring was determined for 83-86 relative to $\mathbf{9 7}$ and $\mathbf{9 8}$. A blue-shift as high as $88 \mathrm{~nm}$ was measured between the absorption maxima of $\mathbf{8 3}$ and $\mathbf{9 8}$. While examining the influence of the substitution pattern on the 1,2,3-triazole ring, the worst results were obtained upon substitution of nitrogen 1 of the triazole, clearly interrupting the conjugation in $\mathbf{8 3}$ and $\mathbf{8 4}$. Conversely, upon substitution of nitrogen 2 of the triazole with an electron accepting group, an absorption maximum at $453 \mathrm{~nm}$ was found for $\mathbf{8 6}$, shifted by $53 \mathrm{~nm}$ compared to 83 (see Table 5).

The well-established $N, N$-dimethylaminophenyl group was not the only electron donor to be used for the design of triazolebased push-pull dyes. Another electron-donating group of interest which is extensively used for the design of photoluminescent dyes was also employed, namely fluorene. Small molecules but also polymers ${ }^{55}$ were prepared for their photoluminescence properties. Concerning small molecules, a series of four derivatives 99-101 varying in the substituent attached onto the electron accepting moiety was examined for their absorption and emission properties. ${ }^{56}$ Using the standard conditions of click chemistry, the four compounds were obtained with reaction yields ranging from $72 \%$ for 99 to $79 \%$ for $\mathbf{1 0 0}$ and $\mathbf{1 0 1}$ by making a reaction between 103 with 34, 35 with 104 or 34 with 105 (see Scheme 11). Surprisingly, examination of the absorption properties revealed the absorption maximum for 102 to be blue-shifted compared to 99-101 (295 $\mathrm{nm}$ vs. $300 \mathrm{~nm}$ ), whereas 102 is substituted by the most electron-withdrawing group (see Table 6).

This blue-shift is the opposite situation to what is classically observed upon introduction of a nitro group onto a push-pull chromophore. ${ }^{57,58}$ The authors tentatively assigned this unexpected shift to a reduction of the conjugation length, the electron-accepting group extending from the triazole ring to the aromatic ring. This trend was confirmed by photoluminescence, 102 again exhibiting the most blue-shifted emission ( $334 \mathrm{~nm} v s .353 \mathrm{~nm}$ for 99) (see Table 6). However, 102 was the most emissive compound of the series, its photoluminescence quantum yield peaking at $0.2 \%$.
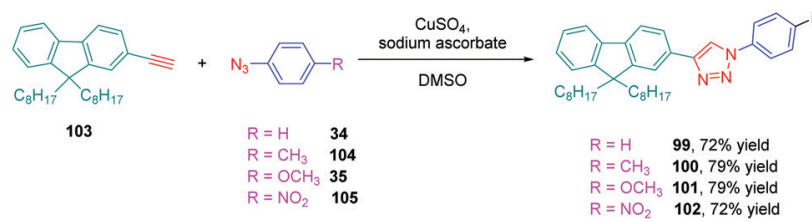

Scheme 11 Click chemistry reaction of four fluorene-triazole-pull molecules 99-102.

103

$$
\begin{array}{ll}
\mathrm{R}=\mathrm{CH}_{3} & 100,79 \% \text { yield } \\
\mathrm{R}=\mathrm{OCH}_{3} & 101,79 \% \text { yield }
\end{array}
$$

Table 6 Physical properties of the four fluorene derivatives 106-113 reported in ref. 56

\begin{tabular}{llllc}
\hline Compounds & $\lambda_{\mathrm{abss}^{a}}{ }^{a}(\mathrm{~nm})$ & $\lambda_{\mathrm{em}}{ }^{b}(\mathrm{~nm})$ & $\Delta \lambda$ Stokes's $(\mathrm{nm})$ & $\varepsilon\left(\mathrm{M}^{-1} \mathrm{~cm}^{-1}\right)$ \\
\hline $\mathbf{9 9}$ & 300 & 353 & 53 & 8100 \\
$\mathbf{1 0 0}$ & 300 & 337 & 37 & 2500 \\
$\mathbf{1 0 1}$ & 300 & 339 & 39 & 11300 \\
$\mathbf{1 0 2}$ & 295 & 334 & 39 & 7300 \\
${ }^{a}$ Recorded in THF with $c=10 \mu \mathrm{M}$ at room temperature. ${ }^{b}$ Upon \\
excitation at $297 \mathrm{~nm}$.
\end{tabular}

The solvatochromism of 99-102 in eight solvents revealed the four dyes to be insensitive to the solvent polarity while examining their absorption characteristics. The opposite situation was found for their emission properties. If the emission of $\mathbf{1 0 2}$ was also insensitive to the solvent polarity, broadening of the absorption spectra was found for $\mathbf{1 0 0}$ and $\mathbf{1 0 1}$ whereas a clear red shift from $342 \mathrm{~nm}$ in toluene to $363 \mathrm{~nm}$ in acetonitrile was found for $\mathbf{9 9}$ upon increasing the solvent polarity. To support the strong shift observed for 99, the presence of excited state intramolecular charge transfer (ESICT) was proposed by the authors. This hypothesis was confirmed while using the Lippert-Mataga model. On the contrary, for $\mathbf{1 0 0}$ and 101, an admixture of locally excited (LE) emission and intramolecular charge transfer emission was proposed to explain the near insensitivity of the emission to the solvent polarity.

Determination of the origin of the photoluminescence properties was performed with another series of dyes 106-113 based on polyaromatic structures..$^{59}$ As the main interest of this study, the authors succeeded in converting non-fluorescent or low emissive compounds into highly emissive dyes by simply realizing a click reaction (see Scheme 12). By making a reaction between 4-ethynyl$N, N$-dimethylaniline 94 and 4-ethynylbenzonitrile 114 with four different aryl azides 35, 105, 115 and 116, eight dyes 106-113 could be obtained with reaction yields ranging from 50 to $67 \%$. As observed for the previous series of dyes, solvatochromism revealed

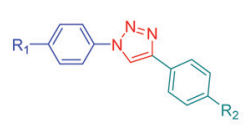

$106: \mathrm{R}_{1}=\mathrm{OMe}, \mathrm{R}_{2}=\mathrm{NMe}_{2}$ $107: R_{1}=O M e, R_{2}=C N$
$108: R_{1}=N_{2}, R_{2}=N^{2} e_{2}$ $108: R_{1}=\mathrm{NO}_{2}, \mathrm{R}_{2}=\mathrm{NMe}_{2}$
$109: \mathrm{NO}_{2}, \mathrm{R}_{2}=\mathrm{CN}$

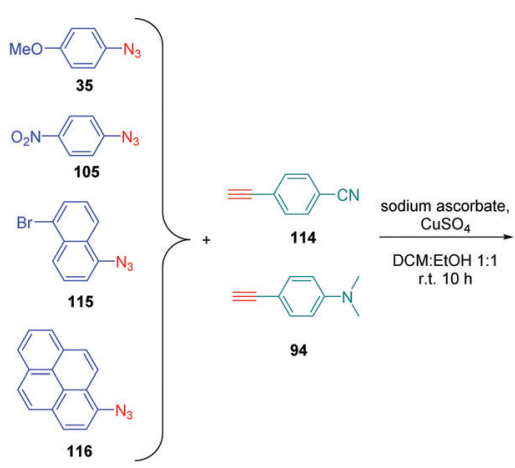

Scheme 12 Chemical structures of 106-113.

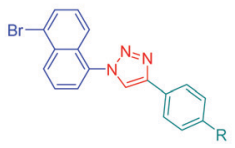
$110: R=\mathrm{NMe}_{2}$
$111: R=C N$
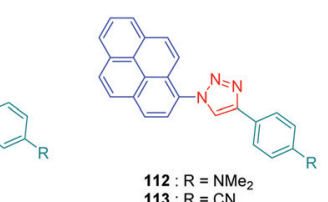

$112: R=\mathrm{NMe}_{2}$
$113: \mathrm{R}=\mathrm{CN}$
$106: R_{1}=O M e, R_{2}=\mathrm{NMe}_{2}, 60 \%$ yield $107: R_{1}=O M e, R_{2}=C N, 67 \%$ yield $108: R_{1}=N_{2}, R_{2}=\mathrm{NMe}_{2}, 50 \%$ yield
$109: R_{1}=N_{2}, R_{2}=C N, 51 \%$ yield $110: R=\mathrm{NMe}_{2}, 85 \%$ yield 111: $R=C N, 56 \%$ yield $112: R=\mathrm{NMe}_{2}, 68 \%$ yield
$113: \mathrm{R}=\mathrm{CN}, 66 \%$ yield 
the absorption maxima for all dyes to be not affected by the solvent polarity contrarily to the photoluminescence maxima. Concerning photoluminescence, an increase of the PLQY with the solvent polarity was demonstrated, evidencing a highly polar excited state. The lack of influence of the solvent polarity on the absorption properties was also indicative of intramolecular charge transfer originating from the lowest-lying excited state. The shift of the emission maximum proved to be relatively important, as exemplified with 106, which showed a shift as high as $122 \mathrm{~nm}$ between hexane and methanol. Comparatively, 111 showed lower sensitivity, the shift being limited to $23 \mathrm{~nm}$. Among the series of dyes, 112, which comprises a pyrene moiety, proved to be the most interesting compound from the point of view of its emission. If a structureless emission peak was found in apolar solvents (cyclohexane and hexane), dual emission could be detected in polar solvents, one of the two peaks being characteristic of the emission of pyrene. In fact, coexistence of ICT emission and LE emission was determined in the PL spectra. Examination of the solvatochromic behaviour by using the Lippert-Mataga model confirmed the previous conclusions. Notably, the different linear correlations revealed the ground state of these dyes to be moderately polar and the emissive state to be highly polar, corresponding to ICT emission. Due to the unique ability of $\mathbf{1 1 2}$ to exhibit dual emission in polar solvents, this compound constitutes thus an excellent candidate for polarity sensing.

Over the years, a wide range of 1,2,3-triazole-based fluorogenic dyes 117-123 have been developed, especially for biolabeling applications as exemplified with the series of compounds presented in Fig. 9. ${ }^{60-65}$ Indeed, in vivo bioimaging and theranostics are two active research fields requiring the rapid development of new structures. ${ }^{66-72}$ In 2009, an extensive study was notably carried out on 102 dyes by making a reaction between 17 azides and 5 different xanthone or xanthene-based fluorophores. ${ }^{73}$ However, conclusions were difficult to establish, no clear trend being detected. Concerning fluorenes, another series of dyes (124-131) was reported in 2013, incorporating diazines as electron acceptors. ${ }^{74}$

In this study, which required hard work for the synthesis with regards to the diversity of structures and the number
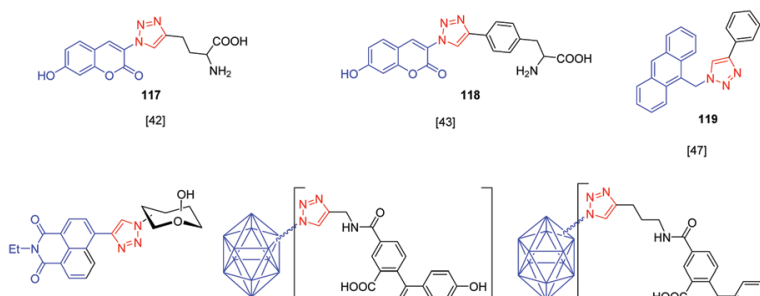

${ }^{120}$

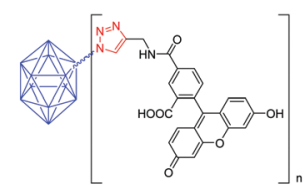

$121 \quad[45]$

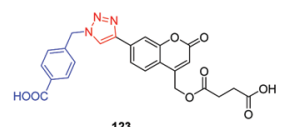

Fig. 9 Series of triazole-based dyes 117-123 used for biolabeling applications.

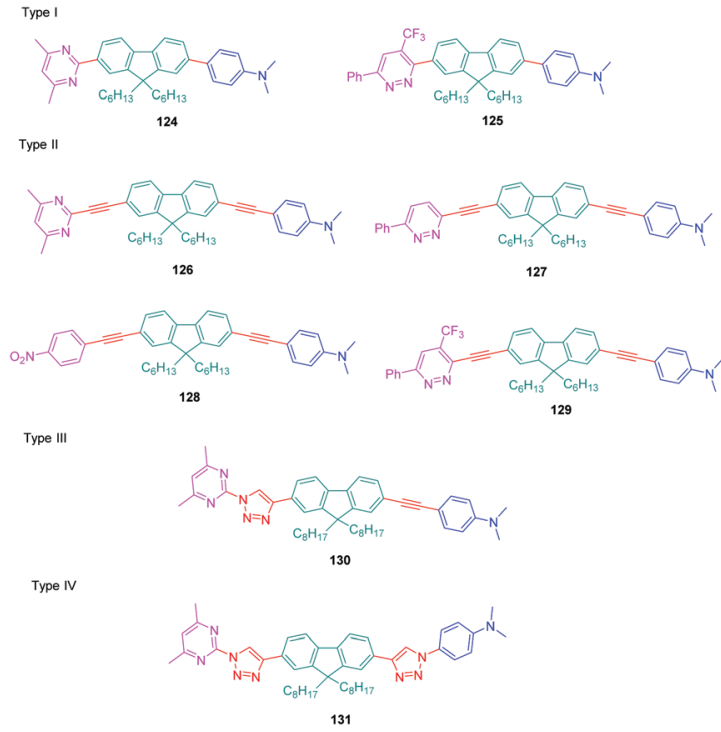

Fig. 10 Structures of the fluorene-based dyes 124-131 comprising a diazine (pyrimidine or pyridazine) as the electron accepting group.

of compounds, four series (I-IV) of D- $\pi-\mathrm{A}$ diads were elaborated, comprising the fluorene unit as a spacer connecting the electronaccepting diazine to the electron-donating $\mathrm{N}, \mathrm{N}$-dimethylaminobenzene, and differing in the length of the $\pi$-conjugated spacer. The structures of the four series of dyes are presented in Fig. 10, comprising as diazine groups pyridazines ${ }^{75}$ or pyrimidines. ${ }^{76}$

In turn, numerous combinations based on different linkages (two triazoles, one triazole and one ethynyl bridge, two ethynyl groups, and two $\sigma$-bonds) could be prepared. A reference compound with a nitro end-group was also prepared for comparison. To create asymmetric structures, 2-bromo-9,9-dihexyl-7-iodo-9H-fluorene 132 proved to be the key element for these different syntheses. Starting from this intermediate, a double Sonogashira cross-coupling reaction with trimethylsilyl-acetylene $\mathbf{1 3 3}$ and triisopropylacetylene 135 enabled the introduction of two ethynyl groups end-capped with protecting groups that could be cleaved selectively with different reaction conditions. Using this strategy, 131 could be obtained after 6 steps in moderate yield (see Scheme 13). A more versatile synthetic route was developed for 105-108 and 109 since a common intermediate could be prepared in three steps starting from 2-bromo-9,9-dihexyl-7-iodo-9H-fluorene 111. Finally, a Sonogashira coupling with the appropriate aryl halide could provide 105-108 with reaction yields ranging from 76 to $86 \%$ (see Scheme 14). Concerning 109, reaction of the common intermediate with azidopyrimidine following a CuAAC procedure could provide 109 in 53\% yield.

A similar approach was developed for the synthesis of $\mathbf{1 4 4}$ and 145 based on a Suzuki cross-coupling reaction this time (see Scheme 15). Despite the presence of two different halogens on 2-bromo-9,9-dihexyl-7-iodo-9H-fluorene 132, the higher reactivity of the iodine atom over the bromine one was not totally respected, $20 \%$ of $4,4^{\prime}$-(9,9-dihexyl-9H-fluorene-2,7-diyl)bis( $N, N$-dimethylbenzenamine) 146 being obtained as a side-product of the reaction of 147 while using 4-dimethylaminobenzeneboronic 


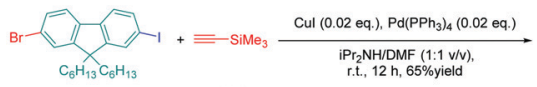

132 133

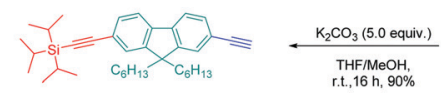

137

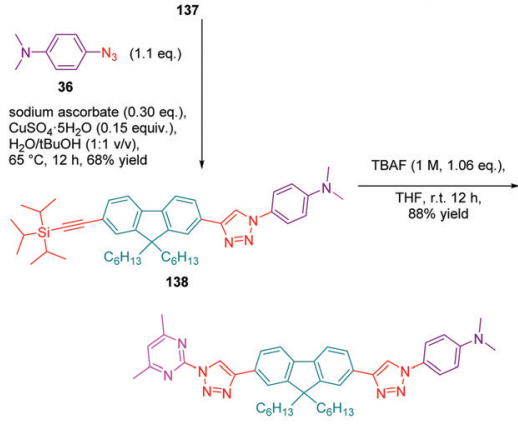

131

Scheme 13 Synthesis of the double triazole-bridged compound 131 starting from 132.

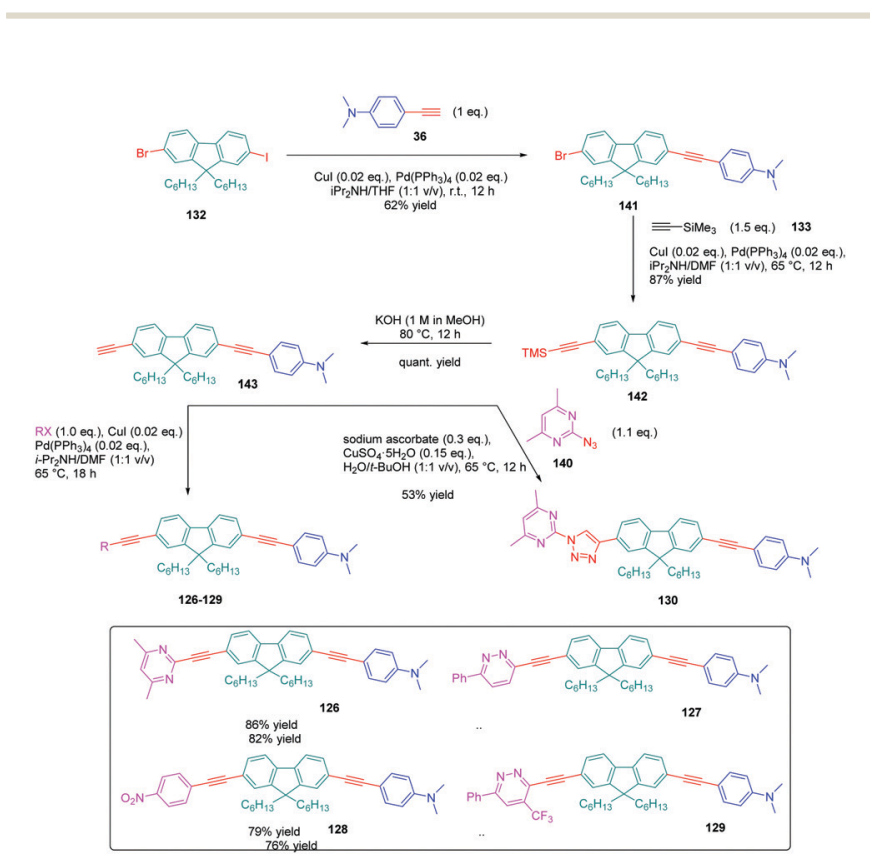

Scheme 14 Synthetic route to compounds 126-130.

acid 148 (see Scheme 15). Surprisingly, a higher yield was obtained for the Suzuki cross coupling reaction of 3-chloro-6-phenyl-4(trifluoromethyl)-pyridazine 149 (44\% yield) than 2-iodo-4,6dimethylpyrimidine 150 (16\% yield). Generally, higher reaction yields are obtained with iodo-derivatives than chloro-derivatives due to the higher polarization of the C-I bond. ${ }^{77-85}$ In the present case, the higher reactivity of 3-chloro-6-phenyl-4-(trifluoromethyl)pyridazine 149 was assigned to the presence of the trifluoromethyl group, activating the $\mathrm{C}-\mathrm{Cl}$ bond.

The UV-visible absorption and photoluminescence properties of the different dyes were examined in dichloromethane and a summary of the photophysical properties is provided in Table 7 .

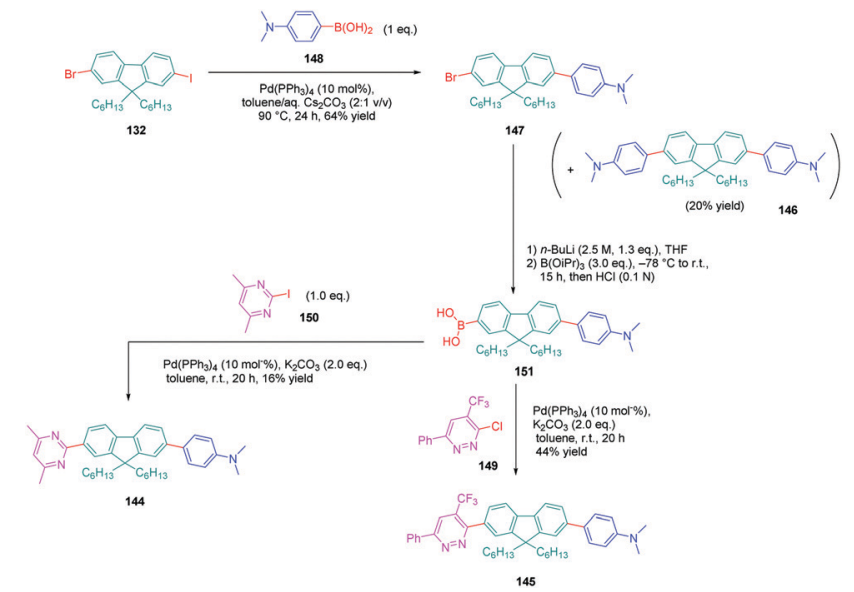

Scheme 15 Successive Suzuki cross coupling reactions enabling the formation of the push-pull derivatives 144 and 145 .

Table 7 Photophysical properties of compounds 126-131, 144 and 145 reported in ref. 74

\begin{tabular}{lllll}
\hline Dyes & $\lambda_{\text {abs }}(\mathrm{nm})$ & $\lambda_{\text {em }}(\mathrm{nm})$ & Stokes shift $\left(\mathrm{cm}^{-1}\right)$ & $\varepsilon\left(\mathrm{M}^{-1} \mathrm{~cm}^{-1}\right)$ \\
\hline $\mathbf{1 3 1}$ & 334 & 422 & 6243 & 82000 \\
$\mathbf{1 3 0}$ & 362 & 450 & 5402 & 71500 \\
$\mathbf{1 2 8}$ & 391 & 474 & 4478 & 51900 \\
$\mathbf{1 2 9}$ & 392 & 500 & 5510 & 74700 \\
$\mathbf{1 2 7}$ & 377 & 539 & 7972 & 58100 \\
$\mathbf{1 2 6}$ & 372 & 515 & 7464 & 52094 \\
$\mathbf{1 4 5}$ & 358 & 423 & 4292 & 39300 \\
$\mathbf{1 4 4}$ & 360 & 483 & 7074 & 58800
\end{tabular}

Considering that all dyes possess the same electron donating group but differ in the electron accepting group and the nature of the conjugated spacer, a comparison could be established.

First, all dyes exhibited an absorption maximum located in the UV-visible range. The maximum absorption was determined at $334 \mathrm{~nm}$ for $\mathbf{1 3 1}$ and $392 \mathrm{~nm}$ for 129, which possess the most red-shifted absorption of the series. For a similar electron-donating moiety, a dramatic decrease of the PLQY was determined for $\mathbf{1 4 5}$. Indeed, compared to $\mathbf{1 4 4}$ for which a PLQY of 0.69 was measured, this value decreased to 0.01 for 145 , this compound being almost not emissive.

This result was assigned to the presence of the $\mathrm{CF}_{3}$-group inducing a torsion of the molecule and breaking the $\pi$-conjugation. The comparison between 126, 127 and 129 and the reference compound 128 revealed an appreciable red-shift of the emission maxima upon replacing the nitrobenzene group of 128 by diazine groups. The most red-shifted emission was found for 127, peaking at $539 \mathrm{~nm}$. Introduction of the electron-withdrawing trifluoromethyl-pyridazine group in $\mathbf{1 2 9}$ did not significantly modify the absorption maximum compared to $\mathbf{1 2 8}$. Finally, using 126, 130, 131 and 144 exhibiting the same electron donating and accepting groups, the influence of the linkage could be determined. Thus, while replacing a single bond by an ethynyl spacer and triazole rings, a significant enhancement of the molar extinction coefficient could be determined, peaking at $82000 \mathrm{M}^{-1} \mathrm{~cm}^{-1}$ for 131. Conversely, a blue-shift of the absorption maximum was 
Table 8 Two photon absorption cross-sections $\delta_{\text {TPA }}$ and wavelength of the maximum TPA cross-section reported in ref. 74

\begin{tabular}{lll}
\hline Dyes & $\lambda_{\text {TPA }}{ }^{a}(\mathrm{~nm})$ & $\delta_{\text {TPA }}{ }^{b}\left(10^{-50} \mathrm{~cm}^{4} \mathrm{~s}_{\text {photon }}{ }^{-1}\right)$ \\
\hline $\mathbf{1 3 1}$ & 700 & 39 \\
$\mathbf{1 3 0}$ & 760 & 148 \\
$\mathbf{1 2 8}$ & 750 & 114 \\
$\mathbf{1 2 9}$ & 740 & 367 \\
$\mathbf{1 2 7}$ & 780 & 269 \\
$\mathbf{1 2 6}$ & 760 & 82 \\
$\mathbf{1 4 4}$ & 700 & 263 \\
$\mathbf{1 4 5}$ & 740 & 123
\end{tabular}

${ }^{a}$ Wavelength of the maximum TPA cross-section. ${ }^{b}$ TPA cross-section.

found for 131 compared to 144 (334 $\mathrm{nm} v s .360 \mathrm{~nm}$ respectively), evidencing a clear interruption of the conjugation when a 1,2,3triazole ring is introduced as the spacer. Finally, two photon absorption (TPA) measurements were realized on these molecules and the results are summarized in Table 8 . By using a femtosecond laser pulse, the solutions could be excited in the 690$940 \mathrm{~nm}$ region. All triazole-based dyes displayed a maximum wavelength for the TPA absorption in the near infrared region. While comparing 126, 130 and 131, the benefits of the presence of one triazole ring were clearly evidenced, the TPA absorption being shifted from 740 to $760 \mathrm{~nm}$. Conversely and as observed for photoluminescence, the presence of two triazole rings in 131 was detrimental for the photophysical properties, a blue-shift as high as $60 \mathrm{~nm}$ being detected for the TPA maximum wavelength between 144 and 131.

The pyrimidine moiety has been at the basis of numerous push-pull dyes, this group constituting a relatively good electron acceptor. Notably, a series of eight push-triazole-pull dyes 152159 differing in the end-groups was synthesized using the click reaction. This series was achieved by click chemistry between the azidopyrimidine 140 and the different alkynes 94 and 160-166 in a mixture of water/tert-butanol, in the presence of copper sulfate and sodium ascorbate, producing the eight dyes 152-159 with reaction yields ranging from 58 to $99 \%$ (see Scheme 16). Here again, two structural analogues of $\mathbf{1 5 2}$ were prepared, the first one (167) resulting from a click reaction between 4,6 dimethyl2-ethynylpyrimidine 168 and 4-azido- $N, N$-dimethylaniline 36. Synthesis of this compound $\mathbf{1 6 7}$ was previously reported in the literature (see Scheme 16). ${ }^{86,87}$

The second one (169) was obtained by a Sonogashira cross coupling reaction of 2-iodo-4,6-dimethylpyrimidine 150 with 4-ethynylaniline $\mathbf{9 4}$, providing the compound in $81 \%$ yield (see Scheme 16).

As anticipated, all dyes exhibited absorption centered in the UV region, ranging from $244 \mathrm{~nm}$ for $\mathbf{1 5 6}$ to $222 \mathrm{~nm}$ for $\mathbf{1 5 3}$. Conversely, part of the molecules could emit in the visible range, from $476 \mathrm{~nm}$ for 153 and 154 to $486 \mathrm{~nm}$ for 152. A major impact of the substitution pattern was demonstrated. Thus, alkylation of the amine group of $\mathbf{1 5 4}$ resulted in a red-shift of both the absorption and the emission properties of $\mathbf{1 5 2}$ and 153 due to an improved electron-donating ability. Conversely, the methoxy group is a less efficient electron donor than a dimethylamino or a diphenylamino group, which was confirmed by the
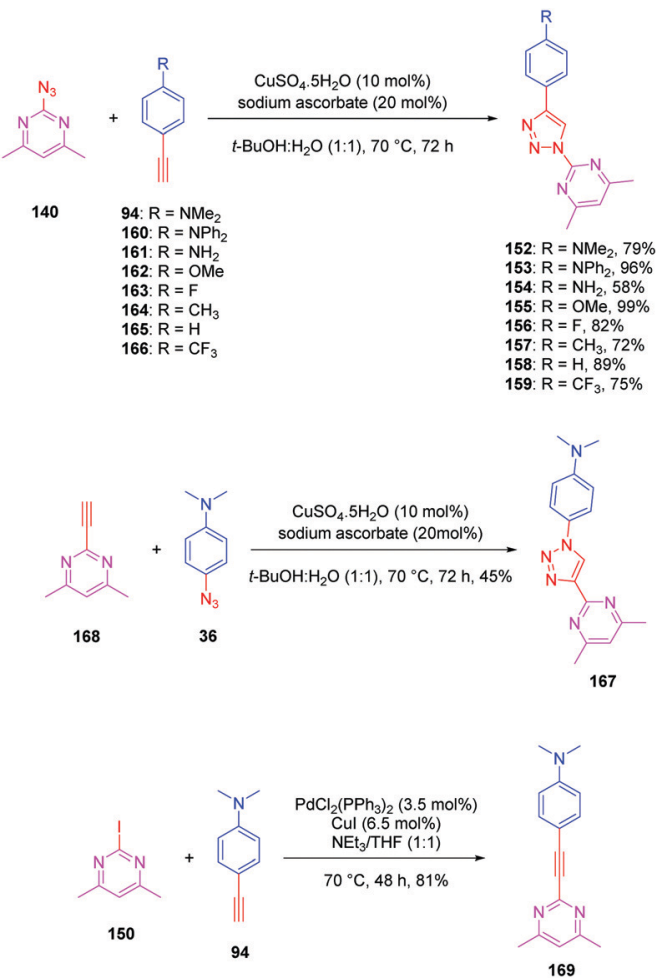

Scheme 16 Synthesis of the triazole-based series 152-159, 167 and 169 and the corresponding reaction yields.

blue-shift of both the absorption and the emission peaks of $\mathbf{1 5 4}$ (see Table 9). While comparing 152 and 167, inversion of the triazole ring in $\mathbf{1 6 7}$ resulted in a blue-shift of the absorption and the emission maxima, together with a decrease of the PLQY.

Table 9 Two photon absorption cross-sections $\delta_{\text {TPA }}$ and wavelength of the maximum TPA cross-section reported in ref. 85

\begin{tabular}{lllllr}
\hline Dyes & $\lambda_{\mathrm{abs}}(\mathrm{nm})$ & $\varepsilon\left(\mathrm{M}^{-1} \mathrm{~cm}^{-1}\right)$ & $\lambda_{\mathrm{em}}(\mathrm{nm})$ & Stokes shift $\left(\mathrm{cm}^{-1}\right)$ & $\Phi_{\mathrm{F}}{ }^{a}$ \\
\hline $\mathbf{1 5 2}$ & 289 & 24386 & 486 & 14026 & 0.47 \\
$\mathbf{1 5 3}$ & 333 & 21427 & 476 & 9022 & 0.45 \\
$\mathbf{1 5 4}$ & 267 & 25698 & 476 & 16445 & 0.30 \\
$\mathbf{1 5 5}$ & 254 & 46211 & 389 & 13663 & 0.01 \\
$\mathbf{1 5 6}$ & 244 & 18069 & 345 & 11998 & $<0.01$ \\
$\mathbf{1 5 7}$ & 250 & 18943 & 364 & 12527 & - \\
$\mathbf{1 5 8}$ & 246 & 25697 & - & - & - \\
$\mathbf{1 5 9}$ & 254 & 20753 & - & - & 0.01 \\
$\mathbf{1 6 7}$ & 250 & 13893 & 434 & 16958 & 0.04 \\
$\mathbf{1 6 9}$ & 357 & 42161 & 447 & 5640 &
\end{tabular}

All spectra were recorded in $\mathrm{CH}_{2} \mathrm{Cl}_{2}$ at $25{ }^{\circ} \mathrm{C} .{ }^{a}$ Quantum yield $( \pm 10 \%)$ of fluorescence determined by using harmane in $0.1 \mathrm{M} \mathrm{H}_{2} \mathrm{SO}_{4}$ as a standard $\left(\Phi_{\mathrm{F}}=0.83\right)$.

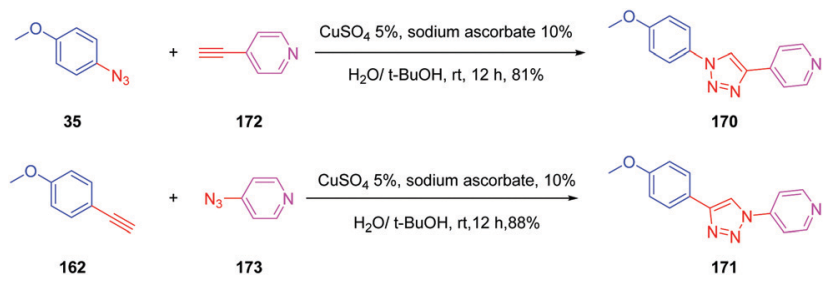

Scheme 17 Synthesis of pyridyloxazole-type fluorophores 170 and 171. 
On replacement of the triazole ring in $\mathbf{1 5 2}$ and $\mathbf{1 6 7}$ by an ethynyl group, a drastic red-shift of the absorption maximum occurred (357 $\mathrm{nm} v$ s. $250 \mathrm{~nm}$ for 167). On the contrary, the small Stokes shift and the low PLQY of 167 confirmed the conclusions previously established from a similar comparison. To get a deeper insight into the optical properties of the different dyes, DFT calculations were carried out. For most of the compounds a
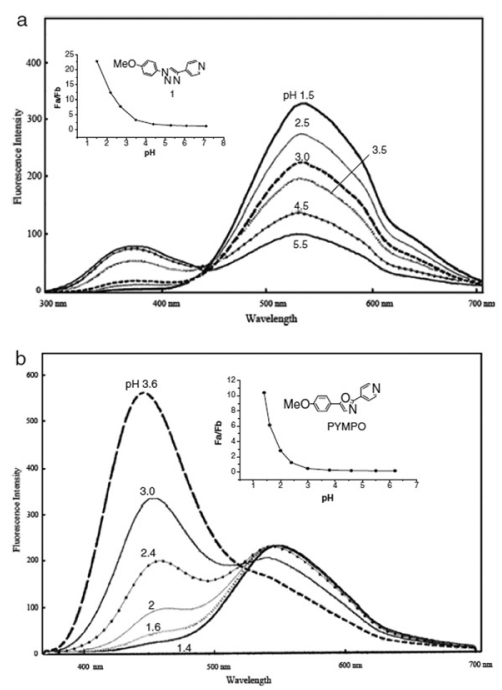

Fig. 11 Fluorescence emission spectra of PYMPO (b) and its triazolebased analogue 170 (a). Reproduced with permission from ref. 88. Copyright 2007, The Chemical Society of Japan (CSJ).

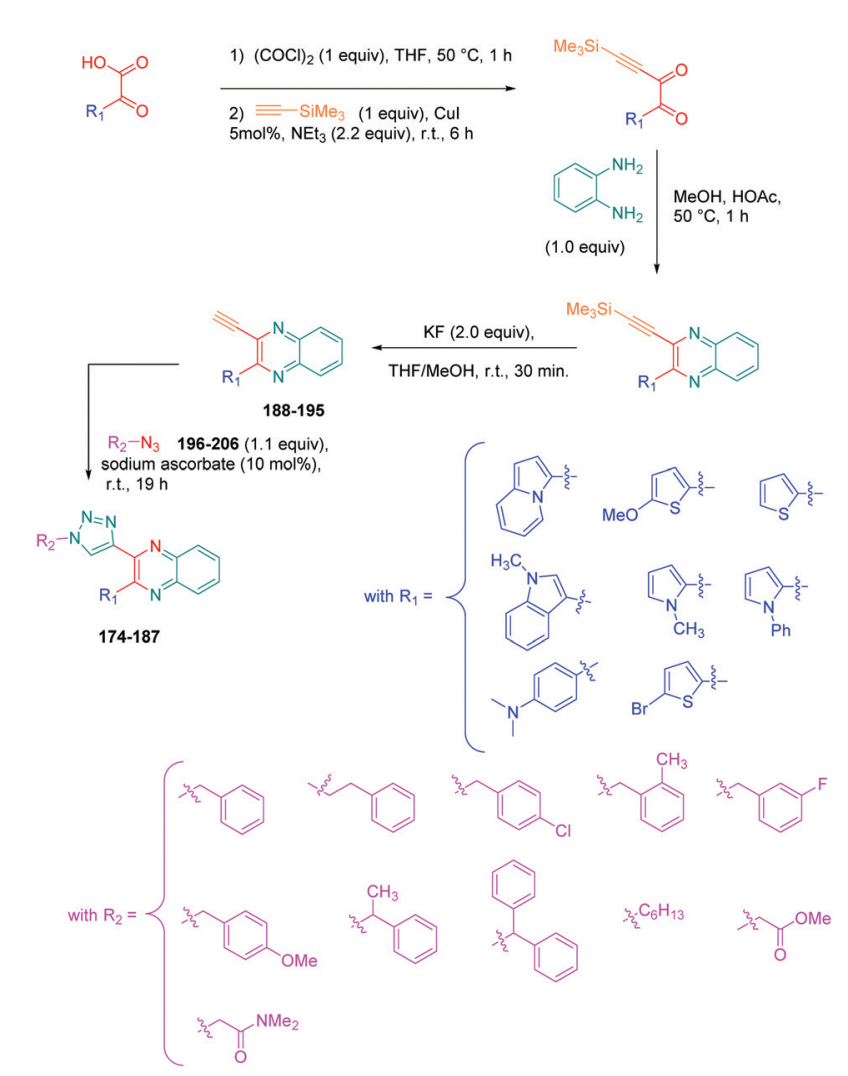

Scheme 18 One pot process for synthesis of quinoxalines 174-187. fully planar structure was found except for 167 , which presented a dihedral angle of $35^{\circ}$ between the phenyl ring and the triazole ring.

This deviation supports the blue-shift observed both in absorption and emission for 167 relative to 152. Theoretical calculations also revealed the absorption spectrum of 169 to be dominated by two main transitions, assigned to the HOMO $\rightarrow$ LUMO and the HOMO-1 $\rightarrow$ LUMO transitions. Considering that for all triazole-based dyes a unique transition corresponding to the HOMO $\rightarrow$ LUMO transition could be theoretically determined, comparison between 169 and 152 or 167 is relatively difficult. Besides, the higher PLQY of $\mathbf{1 5 2}$ compared to 169 is indicative of better electron transfer when a triazole ring is used. Parallel to this, DFT calculations also showed the

Table 10 Two photon absorption cross-sections $\delta_{\text {TPA }}$ and wavelength of the maximum TPA cross-section reported in ref. 91

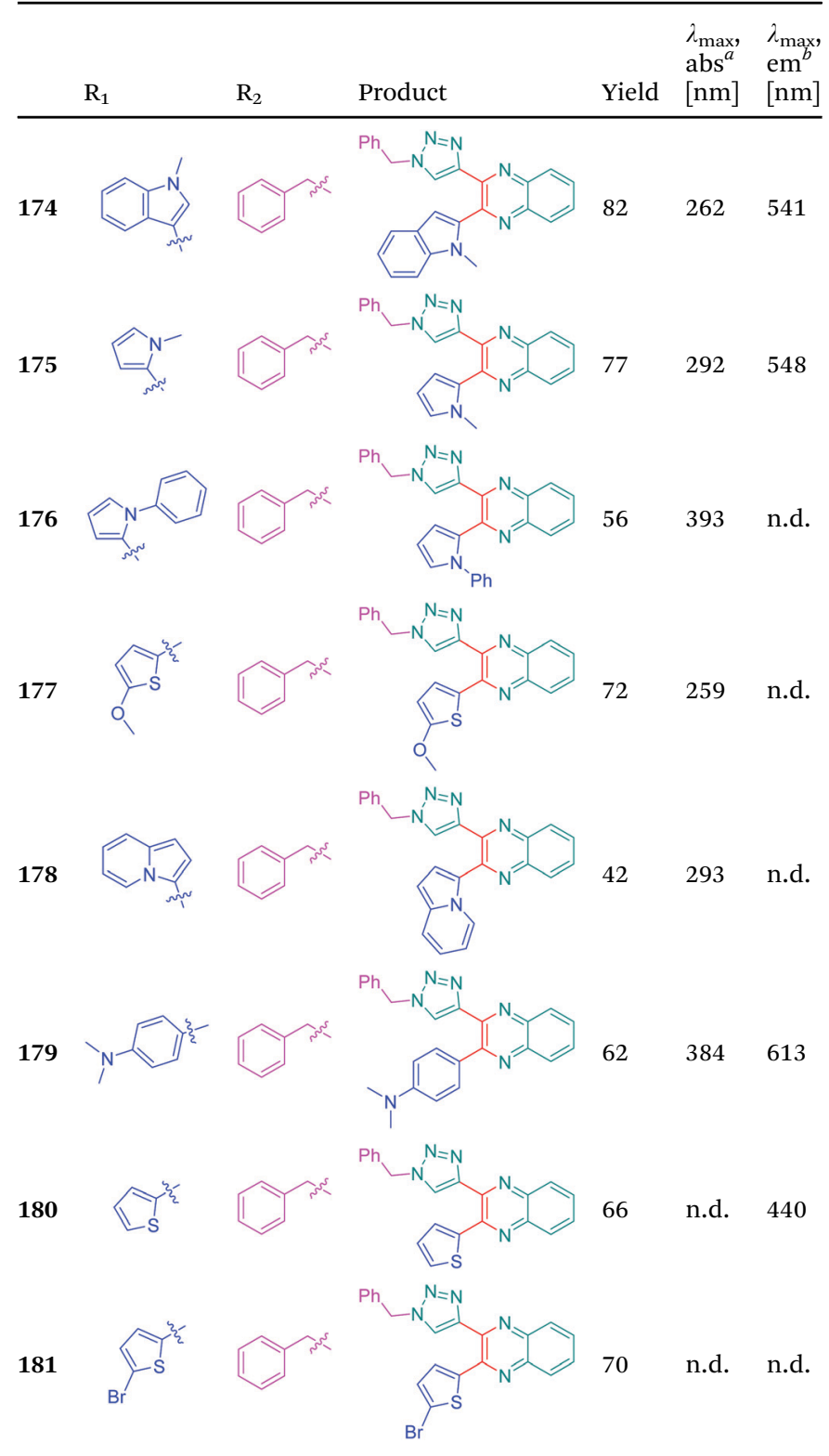

n.d.: not determined. ${ }^{a}$ Recorded in $\mathrm{CH}_{2} \mathrm{Cl}_{2}, C=10^{-5} \mathrm{M}$ at $T=293 \mathrm{~K}$. ${ }^{b}$ Recorded in $\mathrm{CH}_{2} \mathrm{Cl}_{2}$. 
View Article Online

NJC

Perspective

electron density of $\mathbf{1 5 2}$ to be more separated than in $\mathbf{1 6 9}$. Indeed, if the LUMO level of $\mathbf{1 6 9}$ extends over the phenyl ring of the donor, conversely, for 152, the LUMO level is strictly confined on the electron accepting group. In this context, a higher electronic redistribution occurs upon excitation of $\mathbf{1 5 2}$ compared to $\mathbf{1 6 7}$. The influence of the orientation of the phenyl ring on the optical properties was not limited to diazine-based electron acceptors. Pyridine was also selected as a candidate for carrying out a similar study. ${ }^{88}$ The synthetic route is reported in Scheme 17 and the two dyes $\mathbf{1 7 0}$ and 171 could be obtained with reaction yields close to $90 \%$.

Specifically, 170 and 171 were prepared for their structural analogy to PYMPO, which is a $\mathrm{pH}$ probe characterized by strong emission but which is difficult to prepare ${ }^{89,90}$ Considering that pyridine is highly sensitive to the $\mathrm{pH}$ of the reaction medium and can potentially be protonated under acidic conditions, and that the 1,2,3-triazole ring can be easily formed starting from easily accessible intermediates, $\mathbf{1 7 0}$ and $\mathbf{1 7 1}$ were thus considered as candidates of choice to act as a $\mathrm{pH}$ probe to examine biological samples in viva. Examination of the PL spectra at $\mathrm{pH}$ below 7 revealed the fluorescence intensity of $\mathbf{1 7 0}$ to decrease while increasing the $\mathrm{pH}$. No modification of the emission maxima was also detected while varying the $\mathrm{pH}$. Comparison of the $\mathrm{PL}$ spectra of $\mathbf{1 7 0}$ and $\mathbf{1 7 1}$ revealed a major difference in the number of peaks. Thus, if two peaks could be detected in the PL spectra of 170, a unique peak could be found for 171, irrespective of the $\mathrm{pH}$ (see Fig. 11). Finally, comparison of $\mathbf{1 7 0}$ with PYMPO revealed a 25-fold enhancement of the $\mathrm{pH}$-sensitivity of $\mathbf{1 7 0}$ for $\mathrm{pH}$ ranging from 1.5 to 7.

Luminescent molecules can also be obtained using a complex procedure as exemplified in the following series of fluorophores. ${ }^{91}$ Fourteen 3-triazolylquinoxaline derivatives 174-188 were notably prepared using a glyoxylation-alkynylation-cyclocondensationCu-catalyzed alkyne-azide cycloaddition (GACC-CuAAC) sequence

Table 11 Two photon absorption cross-sections $\delta_{\mathrm{TPA}}$ and wavelength of the maximum TPA cross-section reported in ref. 91

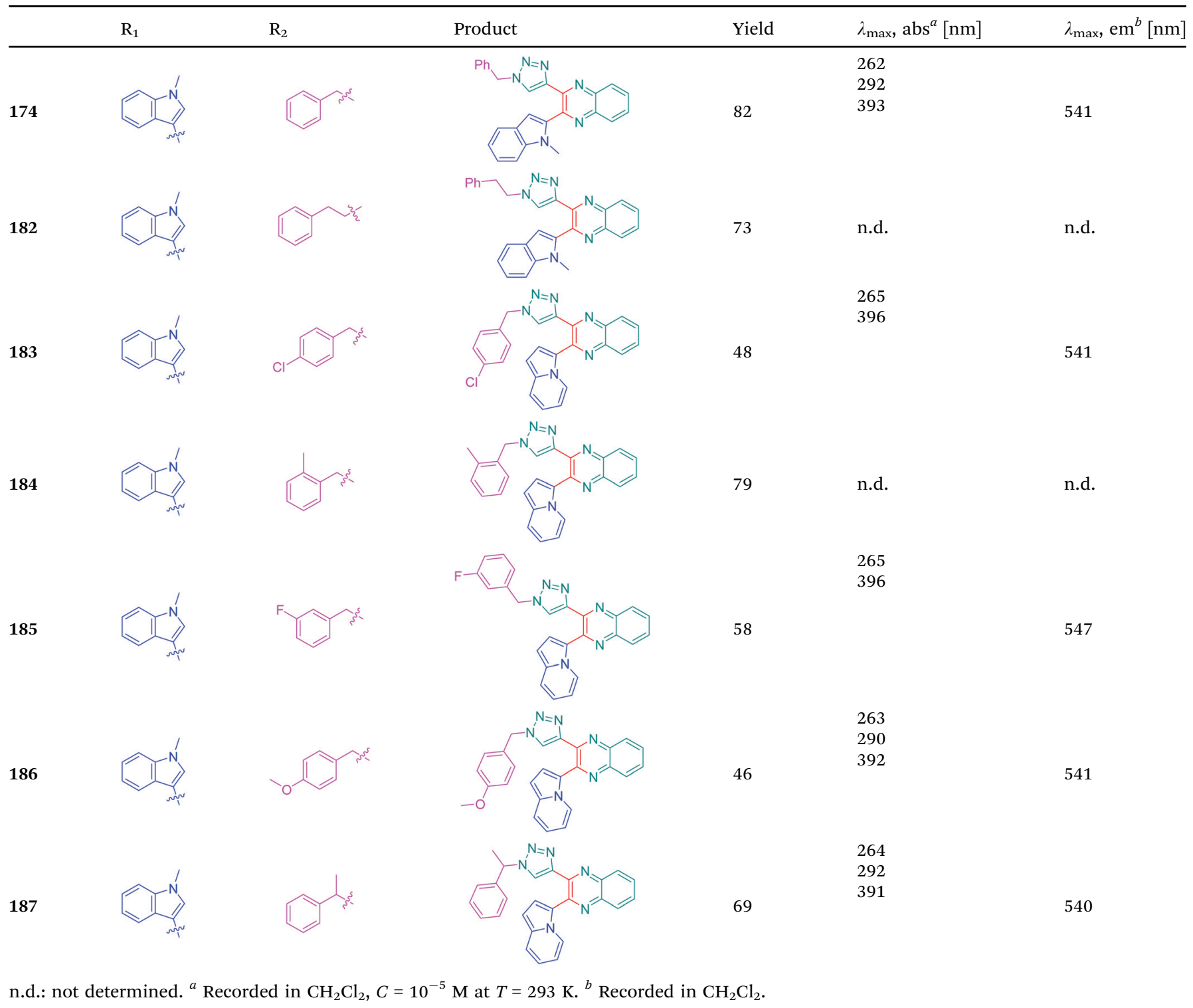

n.d.: not determined. ${ }^{a}$ Recorded in $\mathrm{CH}_{2} \mathrm{Cl}_{2}, C=10^{-5} \mathrm{M}$ at $T=293 \mathrm{~K} .{ }^{b}$ Recorded in $\mathrm{CH}_{2} \mathrm{Cl}_{2}$.

3558

New J. Chem., 2020, 44, 3546-3561

This journal is (c) The Royal Society of Chemistry and the Centre National de la Recherche Scientifique 2020 
requiring five components to proceed. In this one pot reaction, coupling glyoxylation of rich $\pi$-electron heterocycles, Castro alkynylation of acyl chlorides by alkynes, and cyclocondensation of diketones with diphenylamine followed by a click reaction of various azide derivatives 194-204 with alkynes 189-193 furnished 174-188 with reaction yields ranging from $42 \%$ for 178 to $82 \%$ for 174 (see Scheme 18). Two series of molecules can be distinguished. As shown in Table 10, the first series (174-181) differs from the second one by the nature of the electron donating $\pi$-heterocycles. Conversely, the second series (182-187) varies only in the substituents on the triazole ring, the other substituents remaining the same (see Table 11). If change of the electron donating $\pi$-heterocycles could impact the emission wavelength, modification of the pendant group introduced by means of the azide derivatives did not significantly change the photophysical properties of the second series of compounds (see Tables 10 and 11).

In fact, by improving the electron-donating ability of the heterocycle, a bathochromic shift was observed from 2-thienyl (180) to 1-methylpyrrolyl (175), 1-indolyl (174) and finally dimethylaminobenzene (179) groups. Using this strategy, a red-shift of the absorption maximum from $368 \mathrm{~nm}$ for 180 to $393 \mathrm{~nm}$ for $\mathbf{1 7 9}$ was observed. For all dyes, relatively low PLQYs were determined, and this counter-performance was assigned to an internal torsion in the ground and the excited states resulting from the presence of the triazole ring. DFT studies confirmed the lack of influence of the triazolyl substituents on the intramolecular charge transfer, since the HOMO is localized on the rich-electron heterocycle and the LUMO on the quinoxaline core. Moreover, optimization of the geometries of all dyes confirmed the rotation of the triazolyl ring, impacting the conjugation of this substituent with the rest of the molecule. This absence of an effect of the appended triazole ring on the photophysical properties could constitute an advantage for future applications of quinoxalozine compounds in materials or biological applications.

\section{Conclusions}

The discovery of click chemistry at the beginning of the 21st century has clearly reinvented the way to produce molecules. The effect of triazole on the photophysical properties has been clearly evidenced over the years. If the presence of the 1,2,3triazole ring has clearly demonstrated a negative impact on the $\pi$-conjugation when used as a spacer in push-pull dyes, benefits of this group were also demonstrated by providing a higher Stokes shift and higher PLQYs to molecules comprising this group. Besides, by its easiness to be handled and the different studies reporting the preparation of numerous derivatives, the advantages of click chemistry to rapidly develop a wide range of derivatives have been clearly demonstrated. Considering the versatility of click chemistry, the reduction of $\pi$-conjugation in push-pull dyes compared to alkene, alkyne and other $\pi$-conjugated spacers will certainly be solved in the future. Concerning the future applications in which click-chemistry-based dyes could be involved, photopolymerization, which is a rapidly expanding research field, is one of those. Notably, photopolymerists are searching new dyes with optical properties that could be finely tuned allowing to efficiently initiate and control a polymerization process. The same exigence exists for non-linear optical applications with the design of dyes with carefully controlled absorption properties. The versatility of click chemistry will certainly allow during the next decade the design of efficient photoinitiators or NLO dyes.

\section{Conflicts of interest}

There are no conflicts to declare.

\section{Acknowledgements}

This research was funded by Aix-Marseille University and the Centre National de la Recherche Scientifique. The Direction Générale de l'Armement (DGA) is acknowledged for its financial support through the PhD grant of Damien Brunel.

\section{References}

1 C. W. Tornøe, C. Christensen and M. Meldal, J. Org. Chem., 2002, 67, 3057-3064.

2 V. V. Rostovtsev, L. G. Green, V. V. Fokin and K. B. Sharpless, Angew. Chem., Int. Ed., 2002, 41, 2596-2599.

3 R. Huisgen, G. Szeimies and L. Möbius, Chem. Ber., 1967, 100, 2494-2507.

4 X. Jiang, X. Hao, L. Jing, G. Wu, D. Kang, X. Liu and P. Zhan, Expert Opin. Drug Discovery, 2019, 14, 779-789.

5 P. Thirumurugan, D. Matosiuk and K. Jozwiak, Chem. Rev., 2013, 113, 4905-4979.

6 J.-P. Meyer, P. Adumeau, J. S. Lewis and B. M. Zeglis, Bioconjugate Chem., 2016, 27, 2791-2807.

7 A. Marrocchi, A. Facchetti, D. Lanari, S. Santoro and L. Vaccaro, Chem. Sci., 2016, 7, 6298-6308.

8 D. Döhler, P. Michael and W. H. Binder, Acc. Chem. Res., 2017, 50, 2610-2620.

9 K. Kacprzak, I. Skiera, M. Piasecka and Z. Paryzek, Chem. Rev., 2016, 116, 5689-5743.

10 V. K. Tiwari, B. B. Mishra, K. B. Mishra, N. Mishra, A. S. Singh and X. Chen, Chem. Rev., 2016, 116, 3086-3240.

11 A. Saeed, F. A. Larik and P. A. Channar, Res. Chem. Intermed., 2016, 42, 6805-6813.

12 N. G. Aher, V. S. Pore, N. N. Mishra, A. Kumar, P. K. Shukla, A. Sharma and M. K. Bhat, Bioorg. Med. Chem. Lett., 2009, 19, 759-763.

13 M. Meldal and C. W. Tornøe, Chem. Rev., 2008, 108, 2952-3015. 14 J. E. Moses and A. D. Moorhouse, Chem. Soc. Rev., 2007, 36, 1249-1262.

15 M. Juricek, P. H. J. Kouwer and A. E. Rowan, Chem. Commun., 2011, 47, 8740-8749.

16 P. Xiao, W. Hong, Y. Li, F. Dumur, B. Graff, J.-P. Fouassier, D. Gigmes and J. Lalevée, Polym. Chem., 2014, 5, 2293-2300.

17 P. Xiao, F. Dumur, D. Thirion, S. Fagour, A. Vacher, X. Sallenave, B. Graff, J.-P. Fouassier, D. Gigmes and J. Lalevée, Macromolecules, 2013, 46, 6786-6793. 
18 P. Xiao, F. Dumur, T. T. Bui, X. Sallenave, F. Goubard, B. Graff, F. Morlet-Savary, J.-P. Fouassier, D. Gigmes and J. Lalevée, ACS Macro Lett., 2013, 2, 736-740.

19 P. Xiao, F. Dumur, B. Graff, D. Gigmes, J.-P. Fouassier and J. Lalevée, Macromolecules, 2013, 46, 7661-7667.

20 A. Al Mousawi, F. Dumur, J. Toufaily, T. Hamieh, B. Graff, D. Gigmes, J.-P. Fouassier and J. Lalevée, Macromolecules, 2017, 50, 2747-2758.

21 J. Zhang, N. Zivic, F. Dumur, P. Xiao, B. Graff, D. Gigmes, J.-P. Fouassier and J. Lalevée, J. Polym. Sci., Part A: Polym. Chem., 2015, 53, 445-451.

22 P. Xiao, M. Frigoli, F. Dumur, B. Graff, D. Gigmes, J.-P. Fouassier and J. Lalevée, Macromolecules, 2014, 47, 106-112.

23 M.-A. Tehfe, F. Dumur, B. Graff, F. Morlet-Savary, D. Gigmes, J.-P. Fouassier and J. Lalevée, Polym. Chem., 2013, 4, 3866-3875.

24 M. Parent, O. Mongin, K. Kamada, C. Katan and M. BlanchardDesce, Chem. Commun., 2005, 2029-2031.

25 P. D. Zoon, I. H. M. van Stokkum, M. Parent, O. Mongin, M. Blanchard-Desce and A. M. Brouwer, Phys. Chem. Chem. Phys., 2010, 12, 2706-2715.

26 L. Porrès, O. Mongin, C. Katan, M. Charlot, T. Pons, J. Mertz and M. Blanchard-Desce, Org. Lett., 2004, 6, 47-50.

27 M. G. Silly, L. Porrès, O. Mongin, P. A. Chollet and M. BlanchardDesce, Chem. Phys. Lett., 2003, 379, 74-80.

28 H. Qin, S. Wenger, M. Xu, F. Gao, X. Jing, P. Wang, S. M. Zakeeruddin and M. Grätzel, J. Am. Chem. Soc., 2008, 130, 9202-9203.

29 H. Li, K. Fu, A. Hagfeldt, M. Grätzel, S. G. Mhaisalkar and A. C. Grimsdale, Angew. Chem., Int. Ed., 2014, 53, 4085-4088.

30 G. Zhang, H. Bala, Y. Cheng, D. Shi, X. Lv, Q. Yu and P. Wang, Chem. Commun., 2009, 2198-2200.

31 H. Im, S. Kim, C. Park, S.-H. Jang, C.-J. Kim, K. Kim, N.-G. Park and C. Kim, Chem. Commun., 2010, 46, 1335-1337.

32 W. Zeng, Y. Cao, Y. Bai, Y. Wang, Y. Shi, M. Zhang, F. Wang, C. Pan and P. Wang, Chem. Mater., 2010, 22, 1915-1925.

33 P. Blanchard, C. Malacrida, C. Cabanetos, J. Roncali and S. Ludwigs, Polym. Int., 2019, 68, 589-606.

34 R. Rybakiewicz, M. Zagorska and A. Pron, Chem. Pap., 2017, 71, 243-268.

35 A. Cravino, S. Roquet, O. Alévêque, P. Leriche, P. Frère and J. Roncali, Chem. Mater., 2006, 18, 2584-2590.

36 M. Bourass, A. T. Benjelloun, M. Benzakour, M. Mcharfi, F. Jhilal, M. Hamidiband and M. Bouachrine, New J. Chem., 2017, 41, 13336-13346.

37 T. Duan, K. Fan, Y. Fu, C. Zhong, X. Chen, T. Peng and J. Qin, Dyes Pigm., 2012, 94, 28-33.

38 S. Wen, J. Pei, Y. Zhou, P. Li, L. Xue, Y. Li, B. Xu and W. Tian, Macromolecules, 2009, 42, 4977-4984.

39 K. Sharma, V. Sharma and S. S. Sharma, Nanoscale Res. Lett., 2018, 13, 381.

40 F. Lenzmann, J. Krueger, S. Burnside, K. Brooks, M. Grätzel, D. Gal, S. Rühle and D. Cahen, J. Phys. Chem. B, 2001, 105, 6347-6352.

41 P. Kautny, D. Bader, B. Stöger, G. A. Reider, J. Fröhlich and D. Lumpi, Chem. - Eur. J., 2016, 22, 18887-18898.
42 C. Katan, P. Savel, B. M. Wong, T. Roisnel, V. Dorcet, J. L. Fillaut and D. Jacquemin, Phys. Chem. Chem. Phys., 2014, 16, 9064-9073.

43 N. Mataga, Y. Kaifu and M. Koizumi, Bull. Chem. Soc. Jpn., 1956, 29, 465-470.

44 J. L. Oudar and D. S. Chemla, J. Chem. Phys., 1977, 66, 2664-2668.

45 S. Gronowitz and T. Frejd, Chem. Heterocycl. Compd., 1978, 14, 353-367.

46 B. Iddon, Heterocycles, 1983, 20, 1127-1171.

47 T. L. Gilchrist, Adv. Heterocycl. Chem., 1987, 41, 41-74.

48 D. Lumpi, E. Horkel, B. Stoeger, C. Hametner, F. Kubel, G. A. Reider and J. Froehlich, Proc. SPIE, 2011, 8306, 830615/1.

49 D. Lumpi, F. Glöcklhofer, B. Holzer, B. Stöger, C. Hametner, G. A. Reider and J. Fröhlich, Cryst. Growth Des., 2014, 14, 1018-1031.

50 D. Lumpi, J. Steindl, S. Steiner, V. Carl, P. Kautny, M. Schön, F. Glöcklhofer, B. Holzer, B. Stöger, E. Horkel, C. Hametner, G. Reider, M. D. Mihovilovic and J. Fröhlich, Tetrahedron, 2017, 73, 472-480.

51 P. D. Jarowski, Y.-L. Wu, W. B. Schweizer and F. Diederich, Org. Lett., 2008, 10, 3347-3350.

52 K. Staub, G. A. Levina, S. Barlow, T. C. Kowalczyk, L. S. Lackritz, M. Barzoukas, A. Fort and S. R. Marder, J. Mater. Chem., 2003, 13, 825-833.

53 T. Michinobu, J. C. May, J. H. Lim, C. Boudon, J. P. Gisselbrecht, P. Seiler, M. Gross, I. Biaggio and F. Diederich, Chem. Commun., 2005, 737-739.

54 B. B. Frank, P. R. Laporta, B. Breiten, M. C. Kuzyk, P. D. Jarowski, W. B. Schweizer, P. Seiler, I. Biaggio, C. Boudon, J.-P. Gisselbrecht and F. Diederich, Eur. J. Org. Chem., 2011, 4307-4317.

55 D. J. V. C. van Steenis, O. R. P. David, G. F. P. van Strijdonck, J. H. van Maarseveen and J. N. H. Reek, Chem. Commun., 2005, 4333-4335.

56 Y. Zhu, S. Guang, X. Su, H. Xu and D. Xu, Dyes Pigm., 2013, 97, 175-183.

57 G. Kremser, O. T. Hofmann and S. Sax, Monatsh. Chem., 2008, 139, 223-231.

58 Y. L. Liu, J. K. Feng and A. M. Ren, J. Phys. Chem. A, 2008, 112, 3157-3164.

59 S. S. Bag and R. Kundu, J. Org. Chem., 2011, 76, 3348-3356.

60 K. E. Beatty, J. C. Liu, F. Xie, D. C. Dieterich, E. M. Schuman, Q. Wang and D. A. Tirrell, Angew. Chem., Int. Ed., 2006, 45, 7364-7367.

61 K. E. Beatty, F. Xie, Q. Wang and D. A. Tirrell, J. Am. Chem. Soc., 2005, 127, 14150-14151.

62 M. Sawa, T.-L. Hsu, T. Itoh, M. Sugiyama, S. R. Hanson, P. K. Vogt and C.-H. Wong, Proc. Natl. Acad. Sci. U. S. A., 2006, 103, 12371-12376.

63 Q. Wang, T. R. Chan, R. Hilgraf, V. V. Fokin, K. B. Sharpless and M. G. Finn, J. Am. Chem. Soc., 2003, 125, 3192-3193.

64 Z. Zhou and C. J. Fahrni, J. Am. Chem. Soc., 2004, 126, 8862-8863.

65 F. Xie, K. Sivakumar, Q. Zeng, M. A. Bruckman, B. Hodges and Q. Wang, Tetrahedron, 2008, 64, 2906-2914.

66 D. Li, S. Wang, Z. Lei, C. Sun, A. M. El-Toni, M. S. Alhoshan, Y. Fan and F. Zhang, Anal. Chem., 2019, 91, 4771-4779. 
67 F. Ding, C. Li, Y. Xu, J. Li, H. Li, G. Yang and Y. Sun, Adv. Healthcare Mater., 2018, 7, 1800973.

68 R. Zhang, Y. Xu, Y. Zhang, H. S. Kim, A. Sharma, J. Gao, G. Yang, J. S. Kim and Y. Sun, Chem. Sci., 2019, 10, 8348-8353.

69 L. Tua, Y. Xu, Q. Ouyang, X. Li and Y. Sun, Chin. Chem. Lett., 2019, 30, 1731-1737.

70 F. Ding, Y. Fan, Y. Sun and F. Zhang, Adv. Healthcare Mater., 2019, 8, 1900260.

71 F. Ding, Z. Chen, W. Y. Kim, A. Sharma, C. Li, Q. Ouyang, H. Zhu, G. Yang, Y. Sun and J. S. Kim, Chem. Sci., 2019, 10, 7023-7028.

72 Y. Xu, M. Tian, H. Zhang, Y. Xiao, X. Hong and Y. Sun, Chin. Chem. Lett., 2018, 29, 1093-1097.

73 J. Li, M. Hu and S. Q. Yao, Org. Lett., 2009, 11, 3008-3011.

74 C. Denneval, O. Moldovan, C. Baudequin, S. Achelle, P. Baldeck, N. Plé, M. Darabantu and Y. Ramondenc, Eur. J. Org. Chem., 2013, 5591-5602.

75 S. Achelle, N. Plé and A. Turck, RSC Adv., 2011, 1, 364-388. 76 S. Achelle and N. Plé, Org. Synth., 2012, 9, 163-187.

77 A. F. Littke and G. C. Fu, Angew. Chem., Int. Ed., 2002, 41, 4176-4211.

78 B. U. W. Maes, P. Tapolcsányi, C. Meyers and P. Mátyus, Curr. Org. Chem., 2006, 10, 377-417.

79 S. Nara, J. Martinez, C. G. Wermuth and I. Parrot, Synlett, 2006, 3185-3204.
80 A. Turck, N. Plé, L. Mojovic and G. Queguiner, Bull. Soc. Chim. Fr., 1993, 130, 488-492.

81 S. Achelle, N. Plé, A. Turck, J. P. Bouillon and C. Portella, J. Heterocycl. Chem., 2006, 43, 1243-1249.

82 S. Achelle, Y. Ramondenc, F. Marsais and N. Plé, Eur. J. Org. Chem., 2008, 3129-3140.

83 S. Tumkevicius, J. Donkova, I. Baskirova and A. Voitechovicius, J. Heterocycl. Chem., 2009, 46, 960-964.

84 S. Asano, S. Kamioka and Y. Isobe, Tetrahedron, 2012, 68, 272-279.

85 A. S. Cornec, C. Baudequin, C. Fiol-Petit, N. Plé, G. Dupas and Y. Ramondenc, Eur. J. Org. Chem., 2013, 1908-1915.

86 K. D. Grimes, A. Gupte and C. C. Aldrich, Synthesis, 2010, 1441-1448.

87 T. Sakamoto, M. Shiraiwa, Y. Kondo and H. Yamanaka, Synthesis, 1983, 312-314.

88 J. Shi, L. Liu, J. He, X. Meng and Q. Guo, Chem. Lett., 2007, 36, 1142-1143.

89 S. Charier, O. Ruel, J.-B. Baudin, D. Alcor, J.-F. Allemand, A. Meglio and J. Jullien, Angew. Chem., Int. Ed., 2004, 43, 4785.

90 S. Charier, O. Ruel, J.-B. Baudin, D. Alcor, J.-F. Allemand, A. Meglio, L. Jullien and B. Valeur, Chem. - Eur. J., 2006, 12, 1097-1113.

91 F. K. Merkt, K. Pieper, M. Klopotowski, C. Janiak and T. J. J. Müller, Chem. - Eur. J., 2019, 25, 9447-9455. 